Journal of Educational

and Psychological Sciences

Volume (4), Issue (46) : 30 Dec 2020

$P: 40-63$

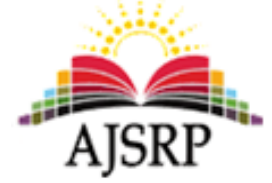

ISSN: 2522-3399

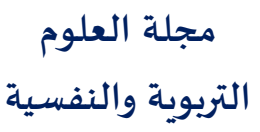

المجلد (4)، العدد (46) : 30 ديسمبر 2020 م

ص: 40 - 403

\title{
The awareness of faculty members at Prince Sattam bin Abdulaziz University of the use of the e-learning platform in light of the outbreak of the COVID 19 virus and their attitudes towards inquiry-based learning
}

\author{
Hala Khairy Abdel-Ghany El-Gohary
}

College of Sciences and Humanities || Prince Sattam bin Abdulaziz University in Al-Kharj || KSA

\begin{abstract}
This study aimed to measure the awareness of faculty members at Prince Sattam bin Abdulaziz University of the use of the e-learning platform in light of the outbreak of the COVID 19 virus and their attitudes towards inquiry-based learning. The researcher used the descriptive approach, semi-experimental, and statistical demographic variables to suit her for the purposes of the study. The study sample consisted of (100) members of the teaching staff of Prince Sattam bin Abdulaziz University, who were chosen in a stratified random manner.

The researcher calculated the stability coefficient of the internal consistency of the questionnaire with its four dimensions and calculated the coefficient of internal consistency of the other questionnaire in its three dimensions. The researcher also used the statistical demographic variables prepared by the Deanship of Information Technology at Prince Sattam bin Abdulaziz University during the period of suspension of the study.

The most important results of the study were as follows: The degree of awareness of faculty members at Prince Sattam bin Abdulaziz University on the e-learning platform "BlackBoard" on the overall questionnaire was high, with an average score of $(3,41)$ and the attitudes of the faculty members at Prince Sattam University in the Kingdom of Saudi Arabia towards inquiry-based learning environment were high, with a mean (3.65), because the survey strategy is an educational process that allows students to use survey skills and support self-learning skills that are To satisfy curiosity, organize knowledge and generate ideas.
\end{abstract}

Recommendations: Searching for obstacles and setting appropriate solutions for them to achieve goals and quality in the educational process via the Internet (Blackboard(, and Developing the skills of faculty members and students alike via the Internet (Blackboard). \&Emphasizing the professional development of a faculty member via the Internet (BlackBoard). Finally Encouraging online inquiry-based learning environment (Blackboard).

Keywords: E-learning Platform - COVID 19 - Inquiry-Based Learning.

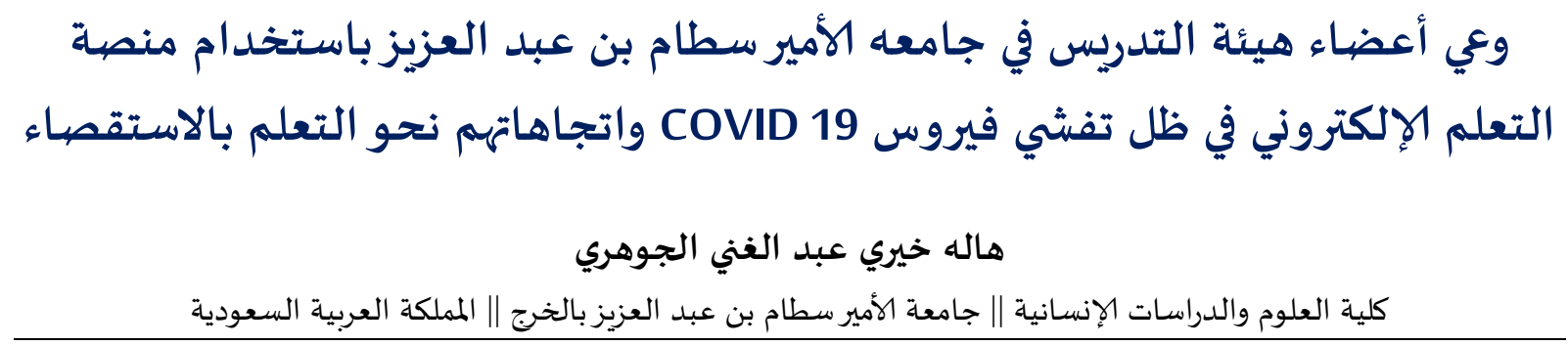

الملخص: هدفت الدراسـة إلى قياس وعي أعضاء هيئة التدريس في جامعه الأمير سطام بن عبد العزيز باستخدام منصة التعلم الإلكتروني

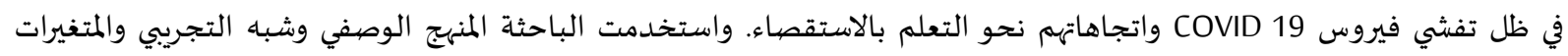


الديموغرافية الإحصائية لمناسبتها لأغراض الدراسة، تكونت عينه الدراسة من (100) عضو من أعضاء هيئة التدريس بجامعة الأمير

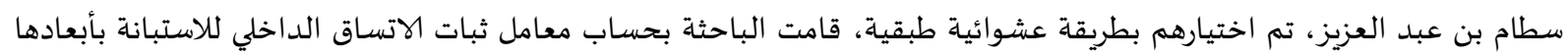

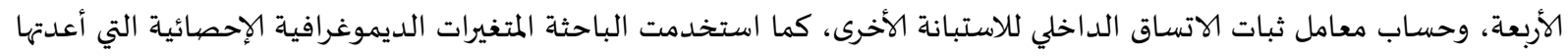

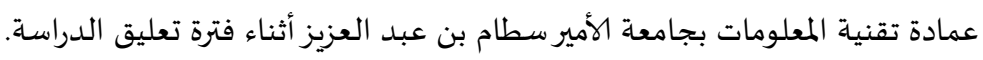

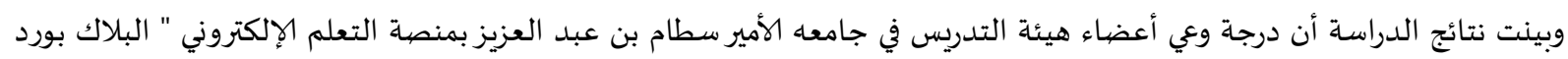

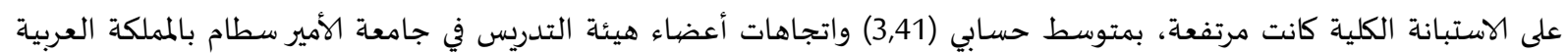

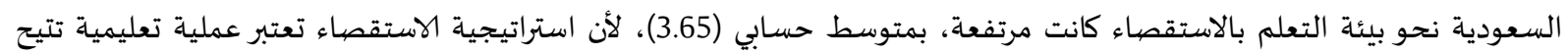

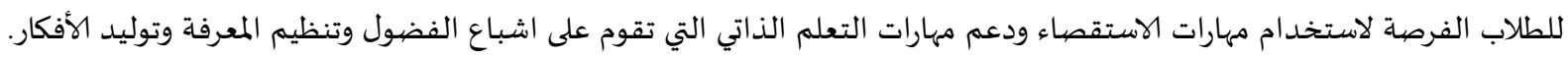

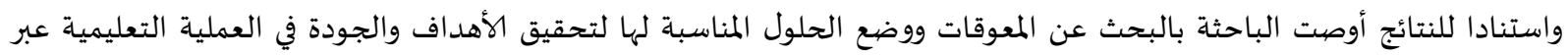

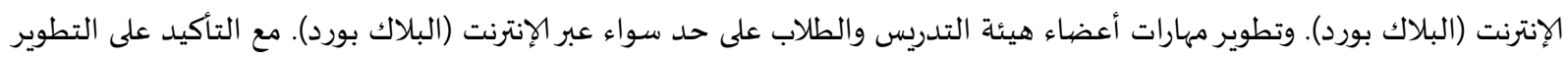

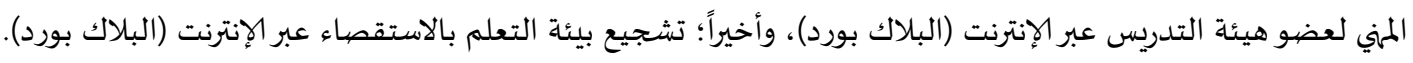

الكلمات المفتاحية: منصة التعلم الإلكتروني - فيروس COVID $19-$ التعلم بالاستقصاء.

مقدمه البحث:

مع استمرار التطور ظهر نمط جديد من التعليم في عصر الفضاء المعلوماتي، قوامه التطور التقني والمعرفي،

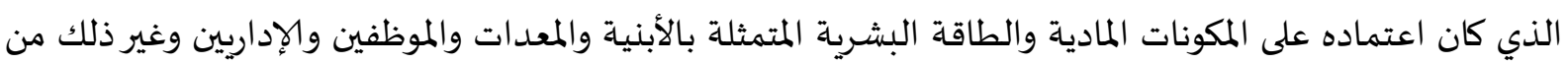

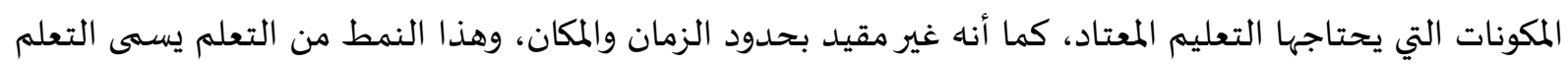

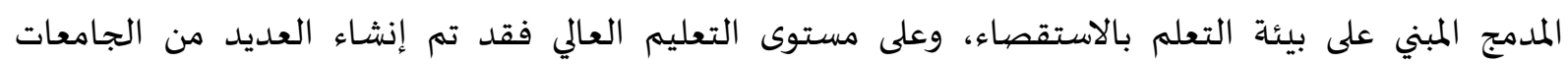

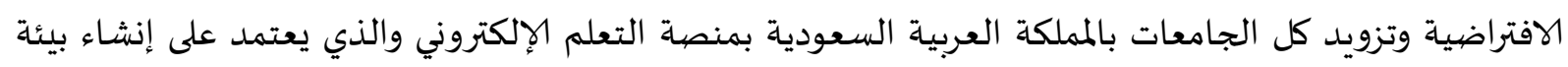

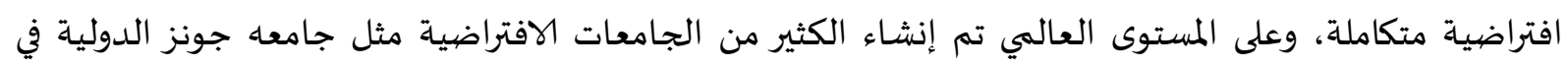

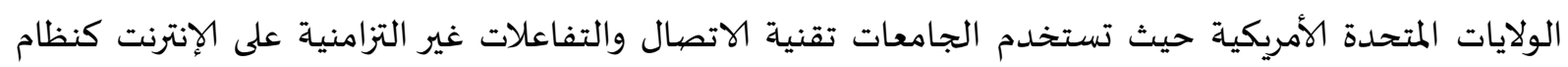
نقل للتعليم والتعلم والجامعة الكندية الافتراضية Deliver System)) نظام التعلم المبرمج (Blended Learning) من حيث تقدم بعض المقررات والبرامج كليا على الإنترنت من خلال

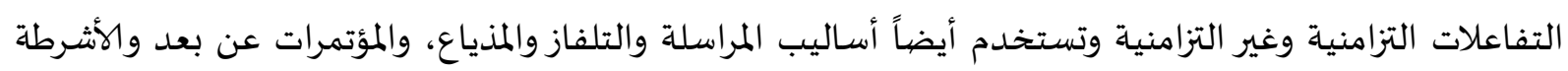
الصوتية، وجامعة كوينز لاند الافتراضية (University of Southern Queens land On Line) (شرف، فاروق، 2006:

يعد التعلم الإلكتروني في البلاد العربية حديث العهد، فهو يشكل تحدياً كبيراً لها، حيث تم إنشاء أول جامعة إلكترونية في مدينة دبي بالأمارات العبية المتحدة وكذلك تم تعميم نظام استخدام التعلم الإلكتروني بوزارة

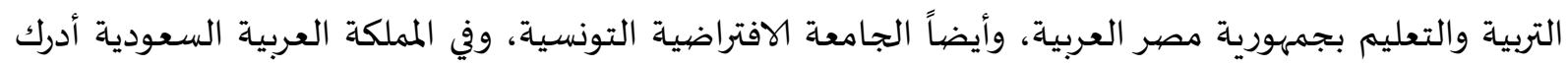

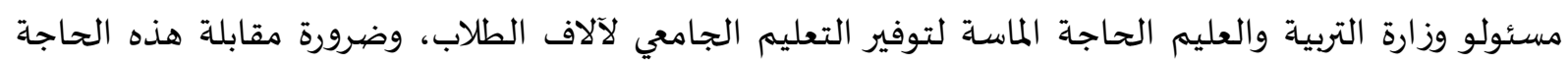

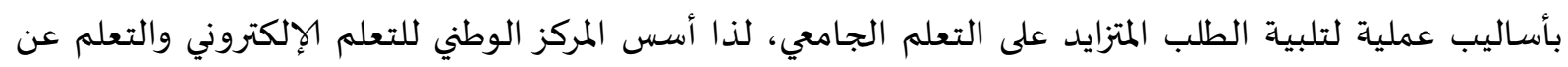

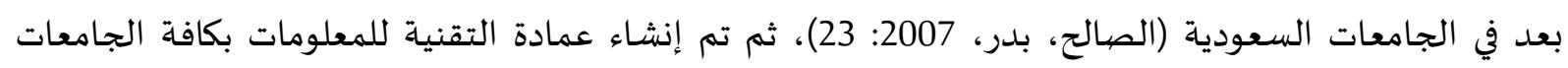

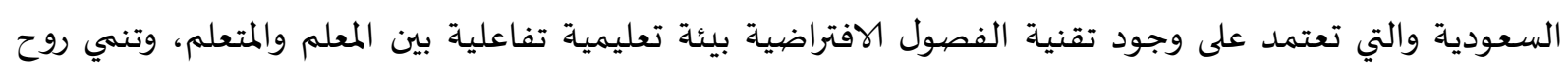

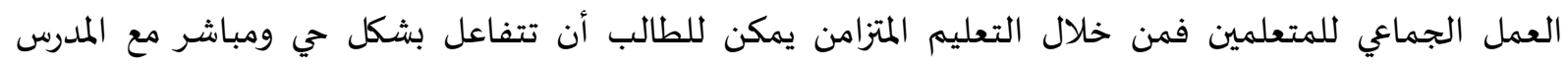

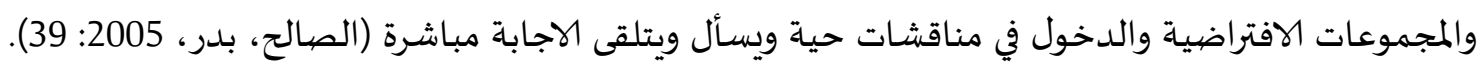


إن نظام العمل بالتعلم المدمج القائم على بيئة التعلم بالاستقصاء يقتضي أولا: نشر المواقع الإكترونية

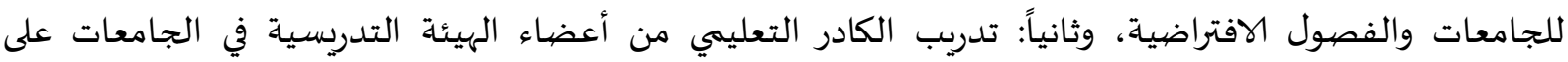

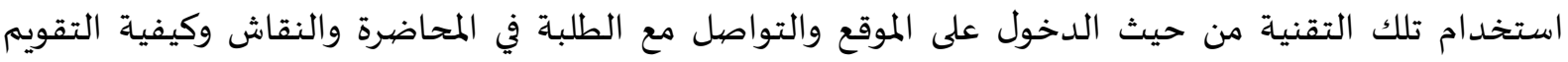
الإلكتروني

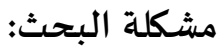

مع استمرار انتشار الفيروس COVID-19 في العديد من دول العالم، أصبح الحفاظ على استمرار التعلم في

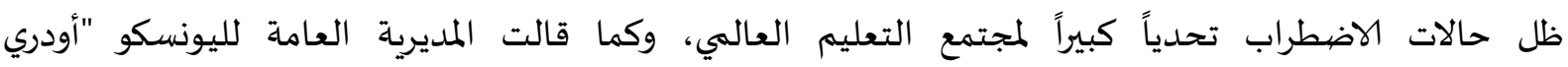

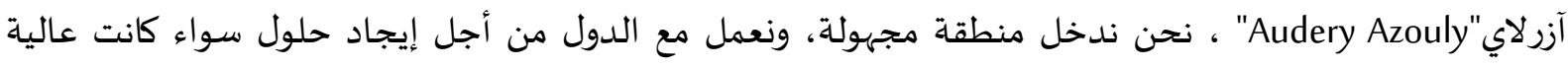

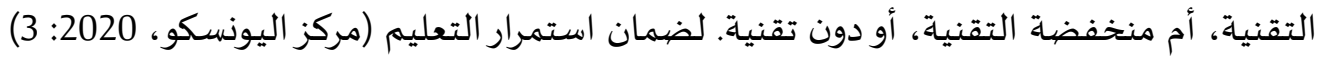
كما تحدثت منظمة الألكسو عن ضرورة " مواصلة جهود المنظمة العربية للتربية والثقافة والعلوم- الكسو الرامية إلى تعزيز استخدام تكنولوجيا المعلومات والاتصال لتطوير التعليم والتعلم وتنمية مجتمعاتنا العربية

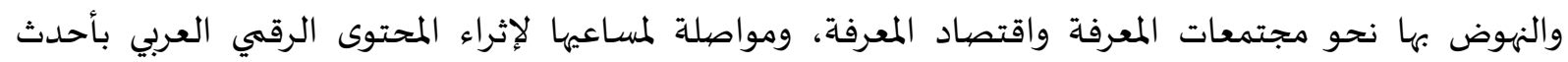

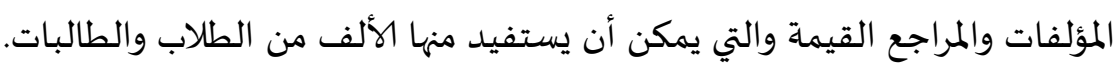

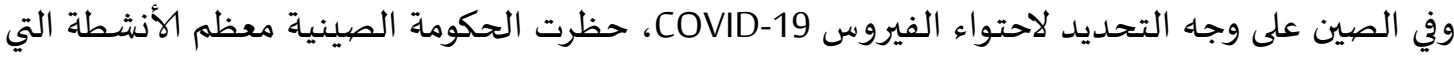

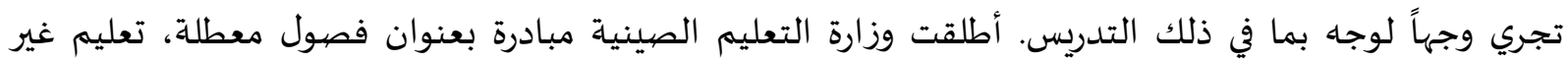
منقطع " لتوفير تعليم مرن عبر الإنترنت لمئات الملايين من الطلاب من منازلهه. انطلاقاً من مبدأ توحيد الجهود، وبناء

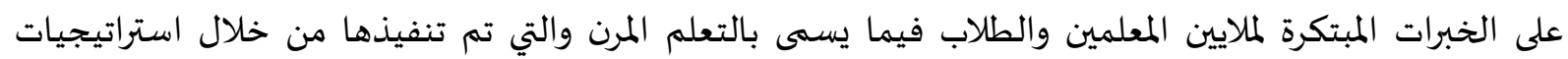

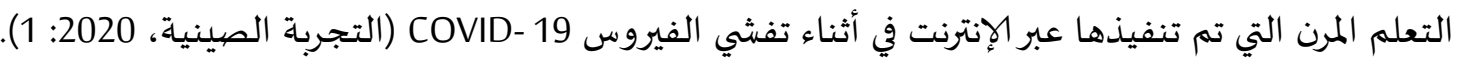

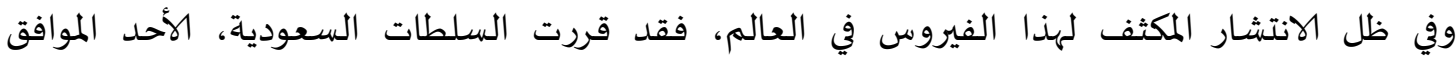

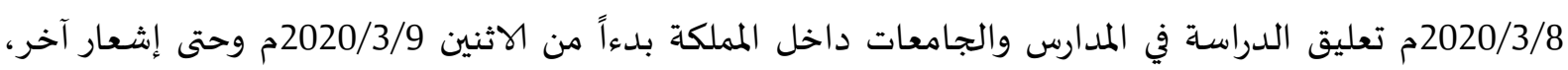

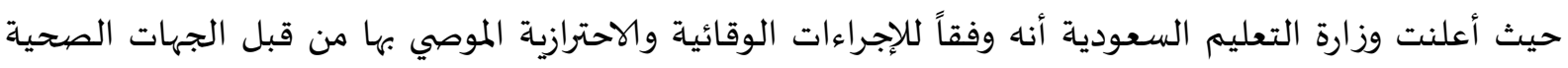
المختصية في المملكة العربية السعودية. وانطلاقاً من الحرص على حمارة العليم الماية صحة الطلاب والطالبات والهيئة التعليمية

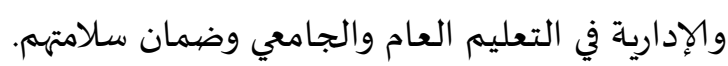
في خلال هذه الفترة قامت الباحثة بإجراء دراسة استطلاعية على عينات مختلفة من أعضاء هيئة التدريس سلواني

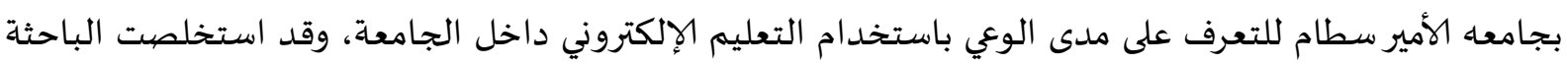
من خلال الدراسة الاستطلاعية ما يلي: - هناك معوقات لدى بعض أعضاء هيئه التدريس في استخدام منصة التعلم الإلكتروني وخصوصيا أساتذة

$$
\text { المقررات النظرية والأدبية. }
$$

يقتصر بعد الأساتذة على استخدام منصة التعلم الإلكتروني فيما يخص وضع درجات الاختبارات وإعلانها

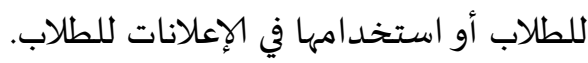

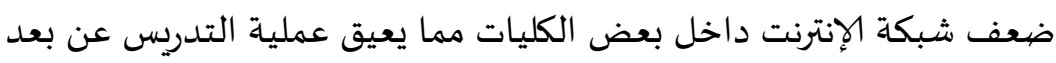

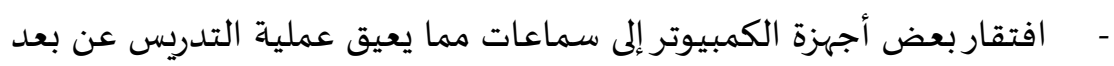

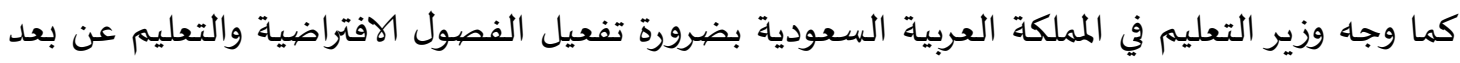
خلال فترة تعليق الدراسية، بما يضمن استمرار العملية التعليمية بفاعلية وجودة من خلال منصية الفصول 
الافتراضية واستخدام المواد الاثرائية الرقمية في متجر التطبيقات لأبل وأندرويد تحت مسهى (منظومة التعليم

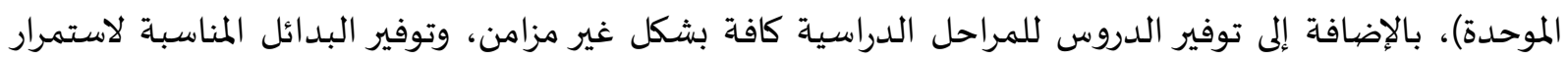

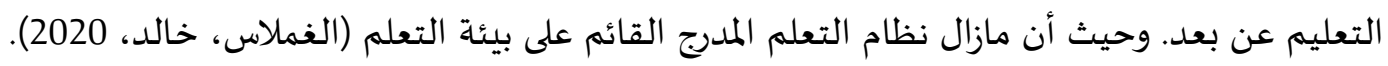

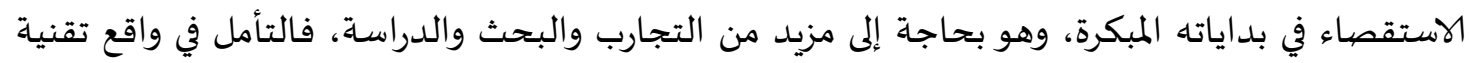

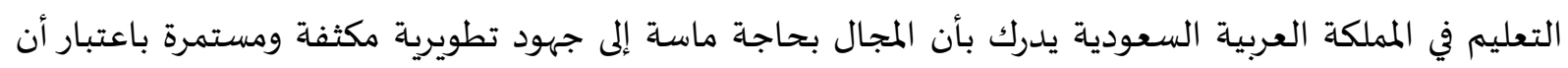

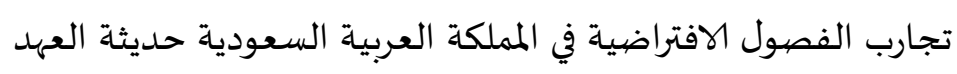
لذا برزت مشكلة هذه الدراسة والتي تسعى لقياس مدى وعي أعضاء هيئة التدريس في الجامعات السعودية المبادية

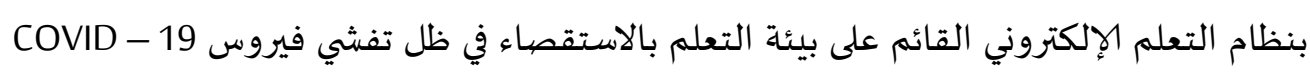

$$
\text { ويمكن عرض مشكلة البحث في الأسئلة الآتية: }
$$

1. ما درجة وعي أعضاء هيئة التدريس بجامعة الأمير سطام بن عبد العيدة العزيز بنظام منصية التعلم الإلكتروني في

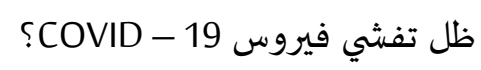

2. ما اتجاهات أعضاء هيئة التدريس بجامعة الأمير سطام بن عبد العزيز نحو بيئة التعلم المدرج القائم على

التعلم بالاستقصاء؟

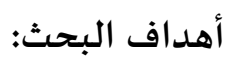

1- قياس الوعي لدى أعضاء هيئة التدريس في جامعه الأمير سطام بن عبد العزيزبنظام منصية التعلم الإلكتروني في

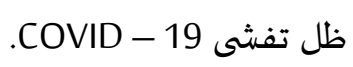

2- قياس اتجاهات أعضاء هيئة التدريس بجامعة الأمير سطام بن عبد العزيزنحو بيئة التعلم بالاستقصاء.

أهمية البحث:

تكتسب هذه الدراسة أهميتها من أهمية موضوعها، حيث تعتبر منصة التعليم الإلكتروني أحد معطيات

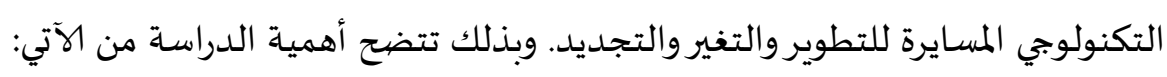

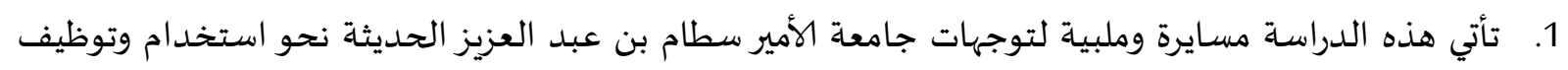

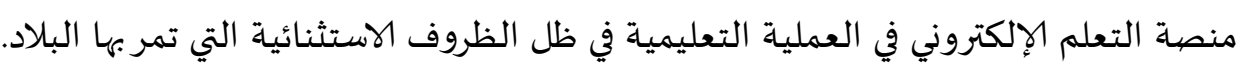

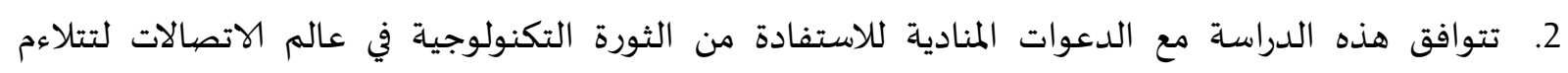

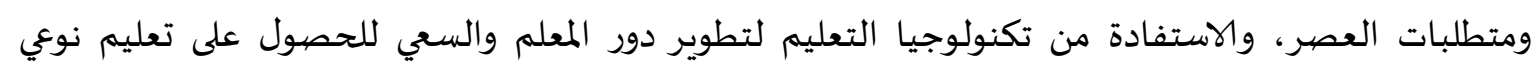

وفعال (الفار، 2002: 36).

3. تسهم في نشر الوعي لدى التربويين بأهمية منصية التعليم الإلكتروني في مجال التعليم والتدريب.

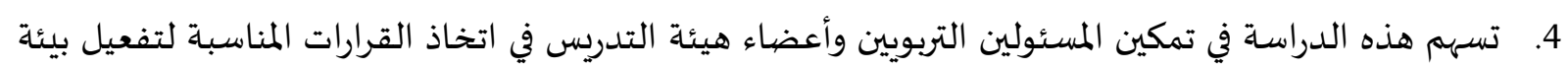

التعلم بالاستقصاء في العملية التعليمية الحديثة وتطويرها.

حدود البحث:

تقتصر حدود الدراسة الحالية على التالي:

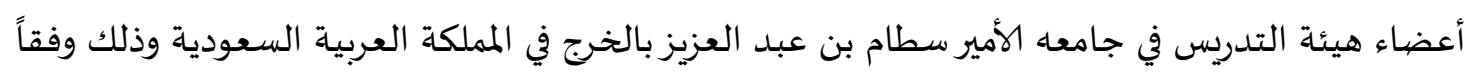

لإحصائيات جامعة الأمير سطام بن عبد العزيزللعام الدراسي (1441/1440هـ) أثناء فتره تعليق الدراسة. 
- O عرفه الكيلاي (2003) بأنه نظام تعليمي يقابل الحاجات الخاصة للأفراد ويتمركز حو المتعلم، ويترتب عليه انفصال شباء دائم خلال العملية التعليمية. O التعريف الاجرائي للباحثة: "هو أحد الأساليب التعليمية التي لا تشترط الوجود المتزامن للمدرب والمشارك في الموقع نفسه، بحيث تم التدريب والتعليم عن طريق وسيط له مجموعة من الجوانب الثقافية والتنظيمية

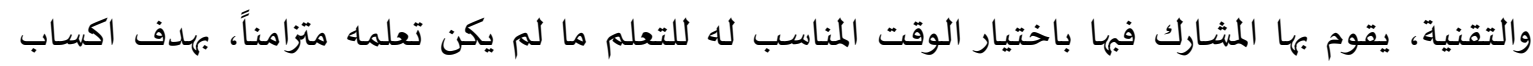

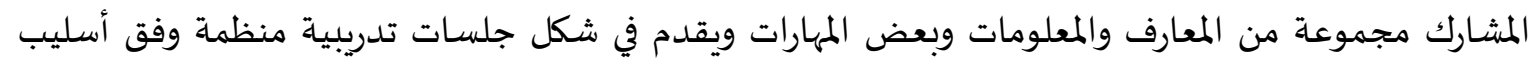

عرفه سالم (2009) بانه منظومة تعليمة لتقديم البرامج التعليمية أو التدربيية للمتعلمين أو المتدربين في أي وقت وفي أي مكان باستخدام تقنية المعلومات والاتصالات التفاعلية مثل (الإنترنت، الإذاعة، القنوات المحلية،

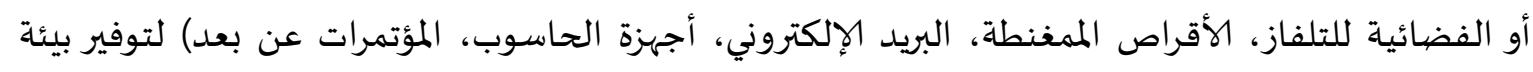

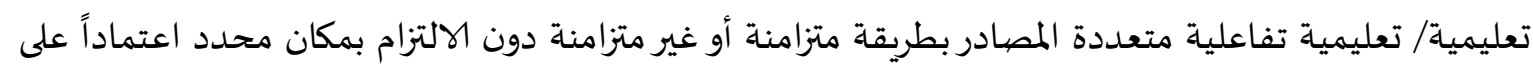

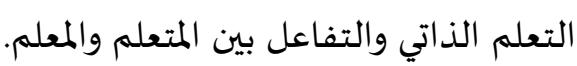
التعريف الإجرائي للباحثة: "هو طريقة تعلم تتم في بيئة تعليمية الكرتونية متطورة، تقوم على مبدأ استخدام

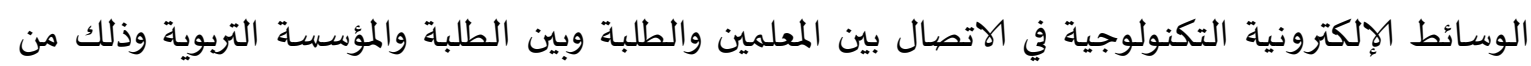

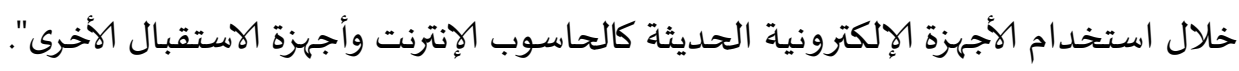

التفاعل المتزامن المباشر (التعريف الإجرائي للباحثة): Synchonusoron - Line Interaction وهو نوع من الاتصال الحي والمباشر في الوقت ذاته (وقت حقيقي وأماكن حقيقية وفيه يتواصل المتعلم مع المعلم المباتئ

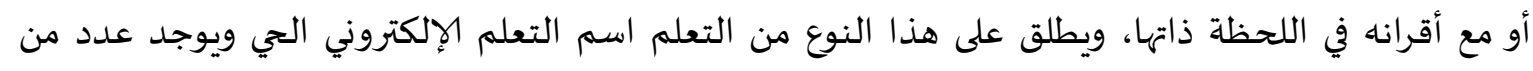

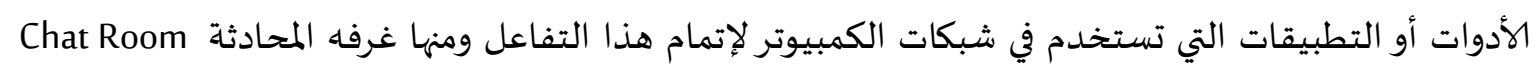

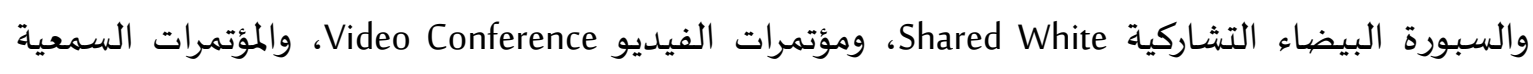
Audio mference

التفاعل غير المتزامن Asy mchronous or off- line Interaction التعريف الإجرائي للباحثة: وفي هذا النوع من التفاعل يتم التواصل بين المعلم والمتعلم أو الأقران ليس في

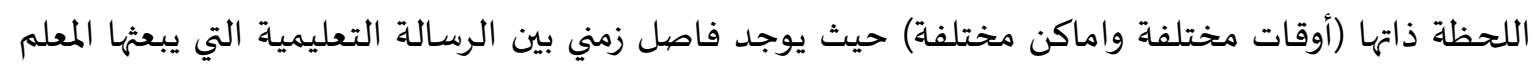

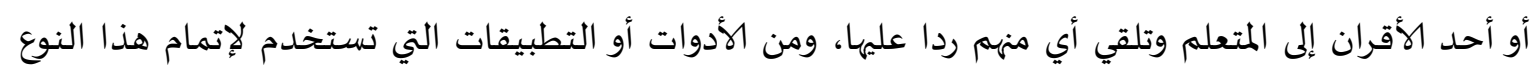

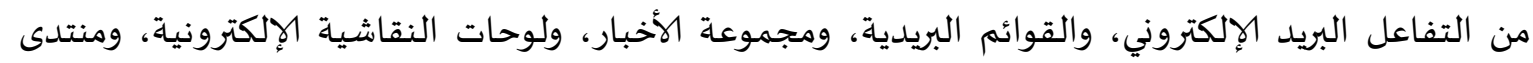

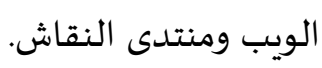

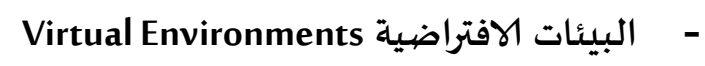
O عرفها زيتون (2005) أهنا بيئات محاكية للواقع بواسطة برمجيات (أدوات) الواقع الافتراضي، وتوجد هذه الواتهات

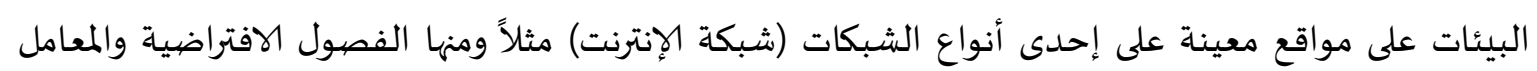


-

O عرفها حشمت (2008) بأهها بيئة افتراضية تزامنية مداره بواسطة المعلم، تتيح التفاعل المباشر بين المعلم

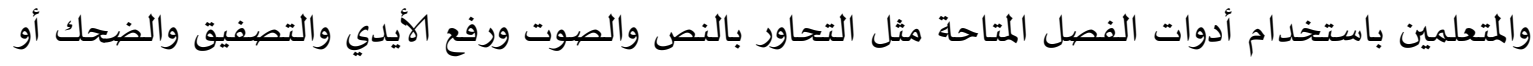

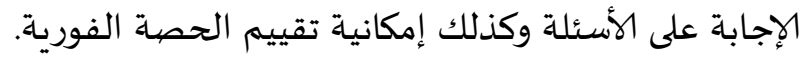

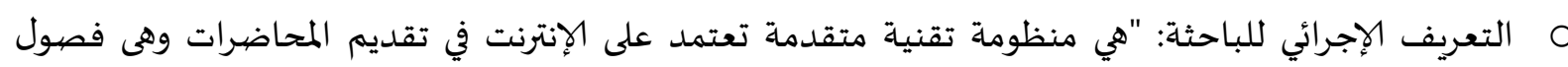

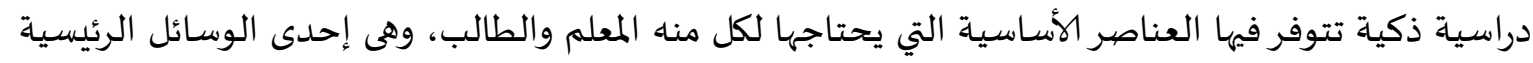

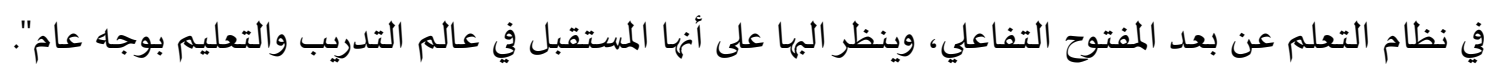

- مبرنامج (Black board) O بلاك بورد هو نظام لإدارة التعلم على الإنترنت مصمم لمساعدة المدرسين والطلاب على التفاعل في المحاضرات

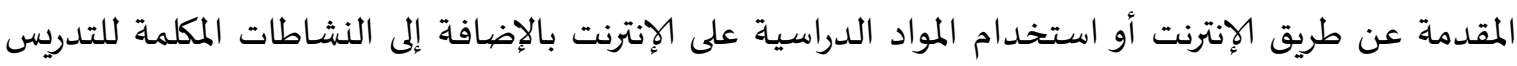

$$
\text { الصفي العادي (وجهاً لوجهاء). }
$$

$$
\text { الإطار النظري والدراسـات السـابقة. }
$$

أولاًَ- الإطار النظري:

يمكن بلاك بورد أعضاء هيئة التدريس من تقدم مواد المقررات الدراسية ومنتديات الحوار والدردشة

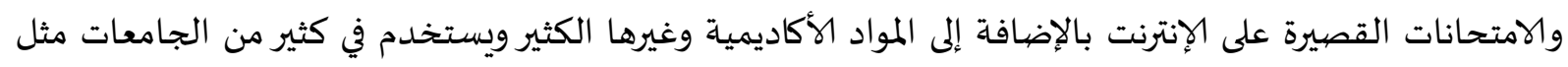

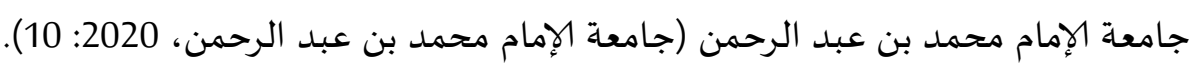

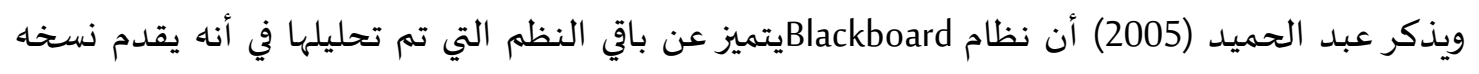

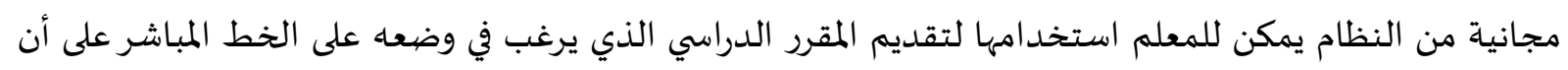

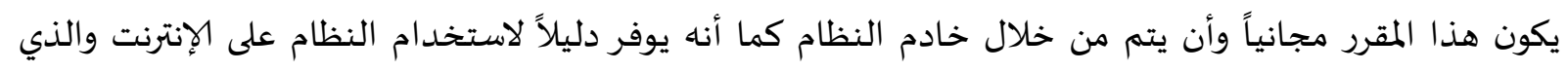

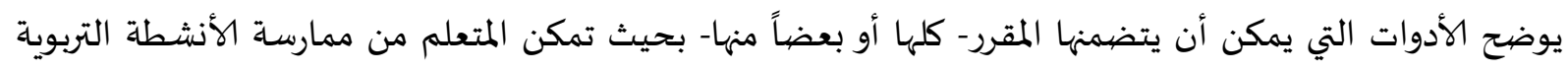

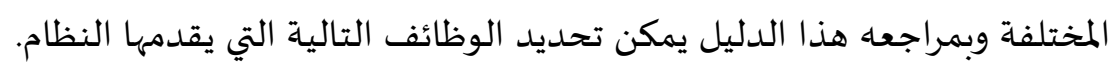
أ- توفير أدوات تفاعل المتعلم مثل الإعلانات - التقويم الزمني - المهام - التقديرات النهائية- دليل المستخدمين-

دفتر العناوين. ب- عرض المحتوى ويتضمن:

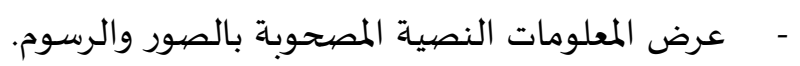

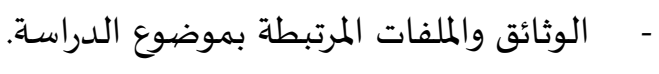

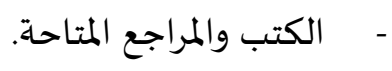
- - الوصلات بالمواقع العامة. ج- وظيفة الاتصال وهي مثل: - ارسال واستقبال الرسائل البريدية. - لوحات النقاش. - - - الفصول الافتراضية. - - مأدوات بناء المقرر. 
-

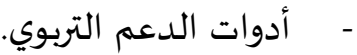

-

المقارنة بين منصية التعلم الإلكتروني والفصل المعتاد التقليدي:

تختلف منصة التعلم الإلكتروني عن الفصيول المعتادة في عدة أمور منها :

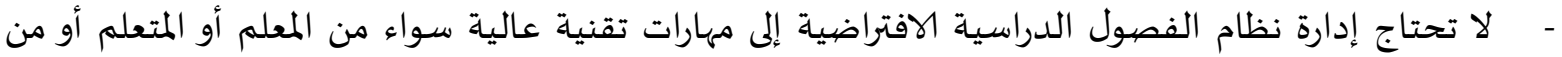

الإدارة التعليمية.

- - يعفى المعلم من الأعباء المتمثلة في المراجعة والتصحيح ورصد الدرجات والتنظيم، مما يتيح له تحسين الأداء والارتقاء بمستواه مع التقنيات الحديثة ومن المعارف واكتساب المهارات والخبرات ويتضمن نظام إدارة التعلم البلاك بورد تقنيات متقدمة وذكية مختلفة مثل التخاطب المباشر (بالنص أو الصيوت أو بالصيوت والنص معاً) والمشاركة المباشرة وارسال الملفات وتبادلها مباشرة بين المعلم وطلبته، وتقنيات أخرى تضمن التفاعل بين المتعلم والمعلم وتتيح التفاعل مع المعلم أو منظم الدورة التعليمية بالصوت والصورة من خلال عرض كامل

للمحتوى على الهواء مباشرة(حشمت، 2008: 35)

دور المعلم والمتعلم في نظام إدارة التعلم الإلكتروني:

التعلم ضمن منصة إدارة التعلم الإلكتروني لا يعني الغاء دور المعلم بل يصبح دوره المعاد أكثر أهمية وأكثر

صعوبة فهو شخص مبدع ذو كفاءة عالية يدير العملية التعليمية باقتدار ويعمل على تحقيق طموحات التقدي التدم والتقنية، حيث يرتبط دور المعلم بأربعة مجالات ه: تصميم التعليم ، وتوظيف التكنولوجيا، وتشجيع تفاعل المتعلمين، وتطوير التعلم الذاتي، والبحث في المكتبات الإكترونية وقواعد البيانات المنتشرة على الشبكة، وهذا الأمر يتطلب امتلاك المعلم لمجموعة من المهارات المتعلقة باستخدام الإنترنت نظم التشغيل ومتطلبات الربط بالشبكة وبعض المشاكل الفنية، ومراعاه خصائص المستفيدين والأهداف التعليمية، وتقديم المعلومات عبر الموقع التعليمي، ومنسق أي يدعم الاتصال والتفاعل بين المستخدمين وبعضهم البعض، والرد على استفسارات المتعلمين، ودور المعلم

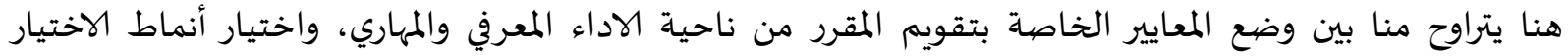

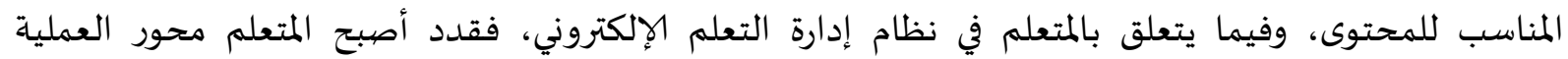

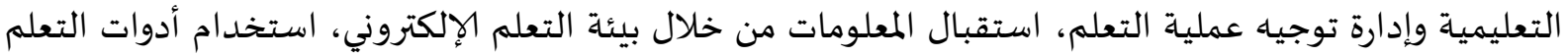

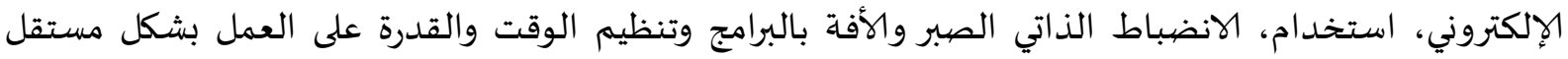
ومراعاة سلوكيات وآداب التعلم في بيئة التعلم الافتراضي.

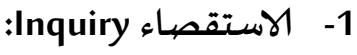

الاستقصاء Inquiry

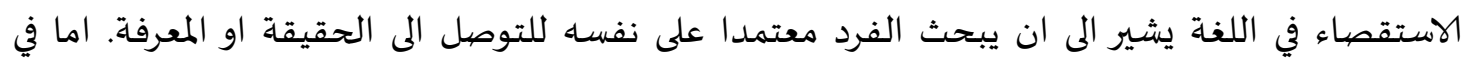

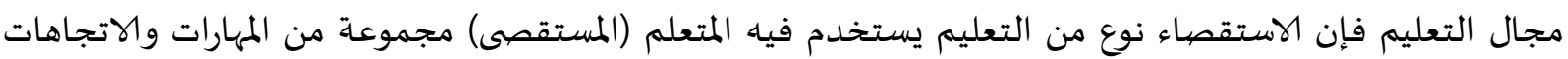

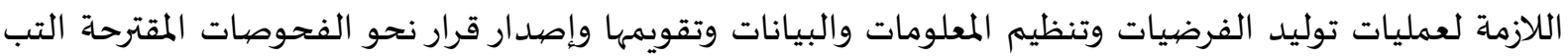

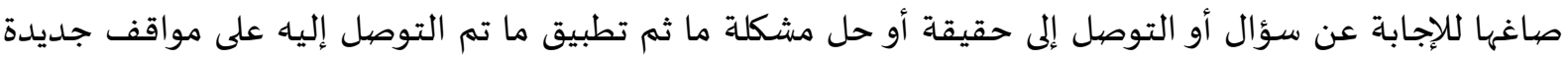

(Mayer,2009,p25) 
وتعريف آخر يرى الاستقصاء نوعاً من السلوك الإنساني الذي يظهره الفرد ويصل به إلى المزيد من المعنى في

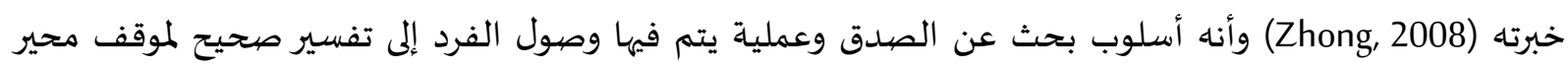
(العمري، 2010: 20).

أما أشمل هذه التعريفات فهو ما تبناه المركز الاستكشافي للاستقصاء

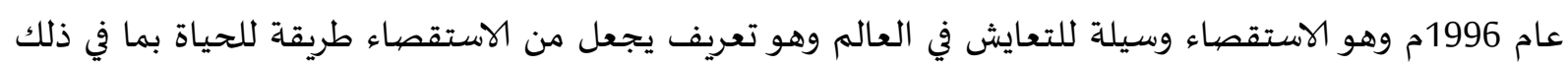
العمل والتعامل مع الناس (Windschitl, 2003, p.45).

2- التعلم بالاستقصاء: Method Inquiry

(التعريف الإجرائي للباحثة): "هو بيئة التعلم التي تدعم الحضور المعرفي والاجتماعي والتدريس للمتعلم".

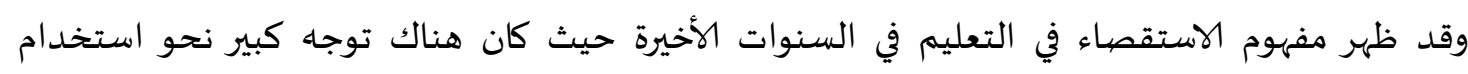

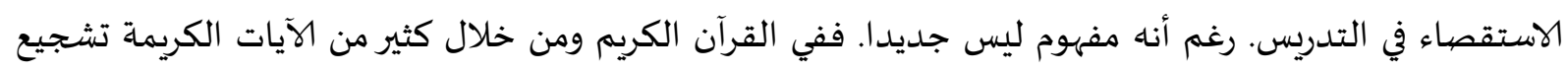

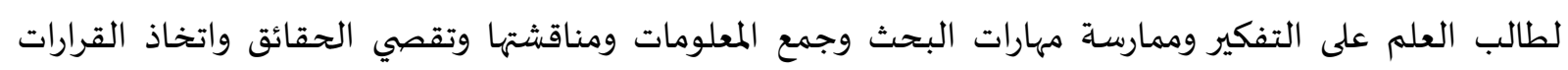
المبنية على الدراسة. والبحث القائمين على الأدلة والبراهين. وهناك أنواع متعددة من الاستقصاء حيث تضمنت أدبيات التربية العملية عدة أنواع من الاستقصاء منها

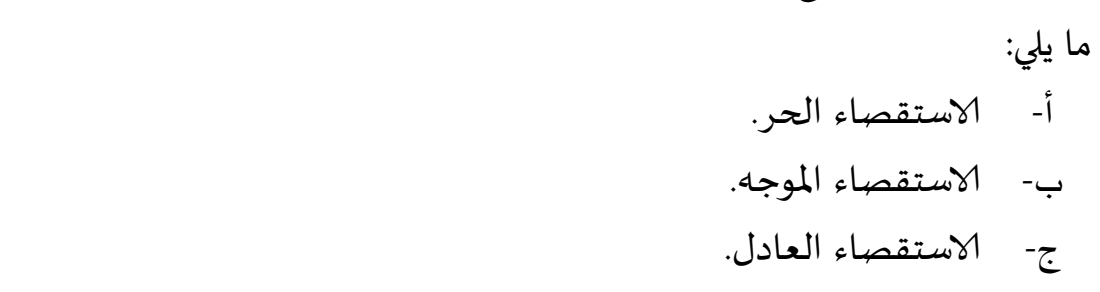

ومن اهم مزايا الاستقصاء (Moore \& Huber, 2001, p5)

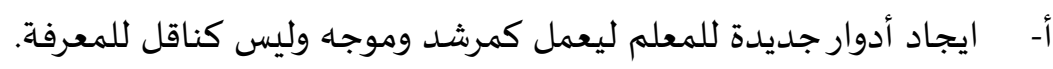

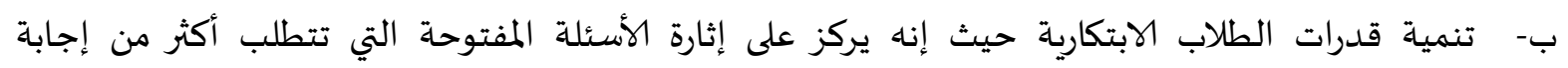
صحيحة.

ج- العمل على استيفاء المعلومات التي يكتسبها للطلاب لدة أطول (ديمومة التعلم)

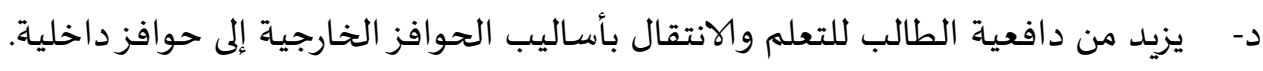

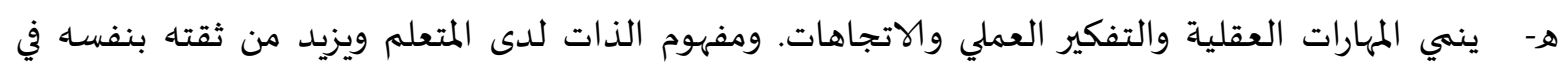

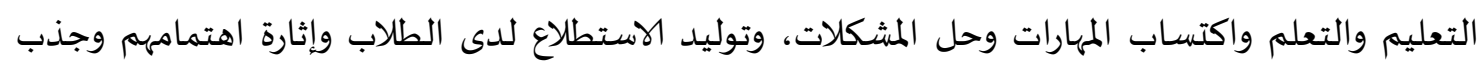

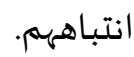

ومن أهم عيوب الاستقصياء ونظراً لأنه يوجد تدريس مثالي مهما كانت رؤيته وفلسفته وأطره الفكرية والمرجعية فإن التدريس والتعلم

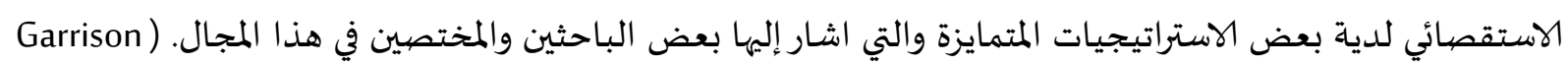

(\&Akyol,2013; Giles, 2008 أ- يحتاج التدريس والتعلم الاستقصائي إلى ذخيرة معرفية للمعلم والطالب على حد السواء.

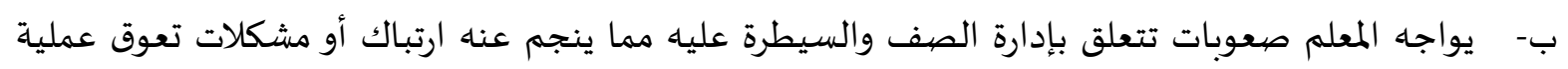
التعلم. 


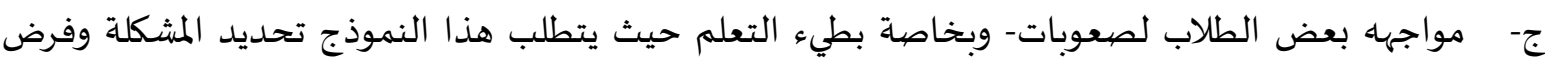
الفروض واختبارها ومن ثم الوصول إلى الاتنتاجات. وكلا تمثل مشكلة بالنسبة للطالب بطيء التعلم

(الهاشم، 2014: 529-528) (19)

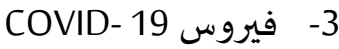

عرفته منظمة الصحة العالمية (2020) أن فيروسات كورونا هي مجموعة كبيرة من الفيروسات التي تسبب المرض للحيوان والإنسان. ومن المعروف أن عدداً من فيروسات كورونا تسبب لدى البشر حالات عدوى الجهاز التنفسي التي تتراوح حدتها من نزلات البرد الشائعة إلى الأمراض الأشد وخاصة مثل متلازمة الشرق الأوسط التنفسية

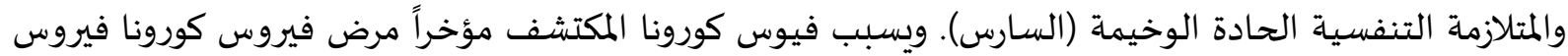
COVID- 19 (تسهيل التعلم المرن عند اضطراب التعليم، التجربة الصينية في الحفاظ على استمرار التعلم في ظل تفشي COVID- 19 (2020).

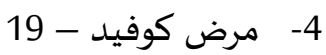

هو مرض معدي يسببه فيروس كورونا المكتشف مؤخراً. لم يكن هناك أي علم بوجود هذا الفيروس وهذا

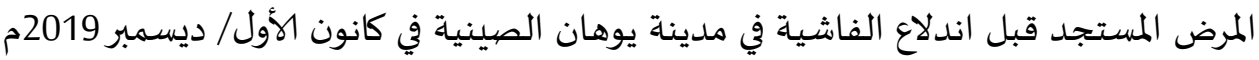
(DICTIONARY OF COVID-19 TERMS,2020,p15)

ثانياً - الدراسـات السابقة:

المحور الأول: دراسـات ترتكز على استخدام التعليم الإكتروني في العملية التعليمية.

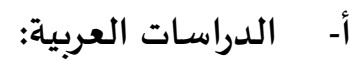

- أجرى العتيبي (2009) دراسة تهدف إلى معرفه واقع استخدام الحاسب الآلي في التدريس بكلية الملك فهد الأمنية من وجهة نظراً أعضاء هيئة التدريس واتجاهاتهم نحوه. وتكونت عينه الدراسة من (230) عضوف هيئة الدائة تدريس.

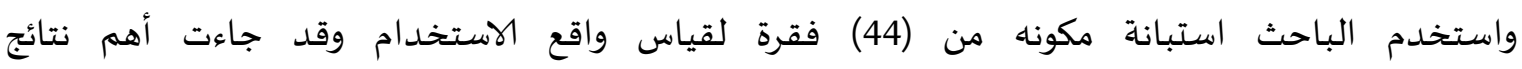

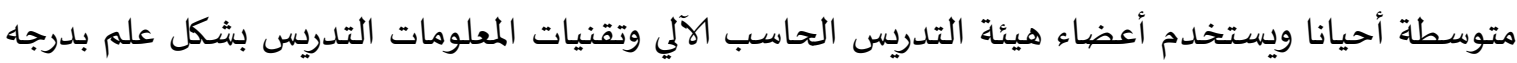
متوسطة أحياناً ويستخدم أعضاء هيئة التدريس بعض ولتينة التقنيات بدرجة كبيرة أو غالباً وهي على الترتيب (أجهزة

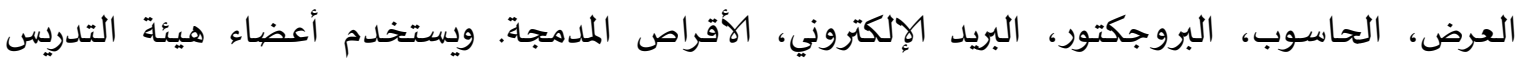

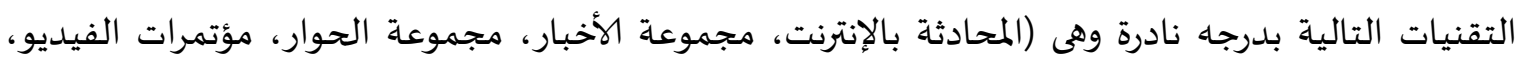

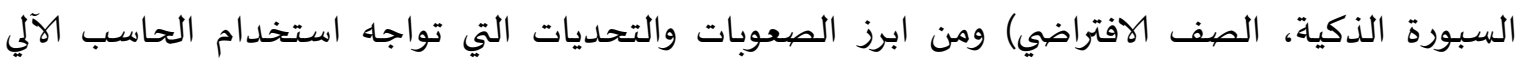

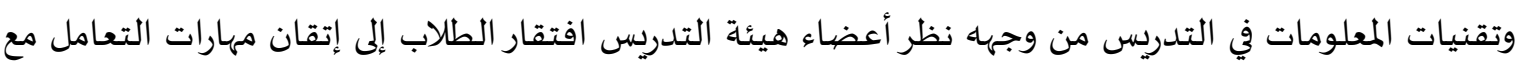

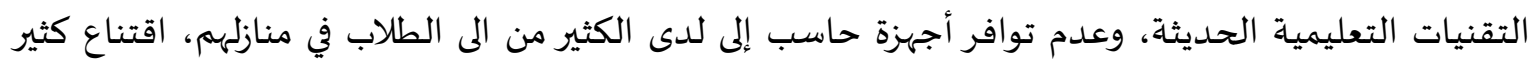

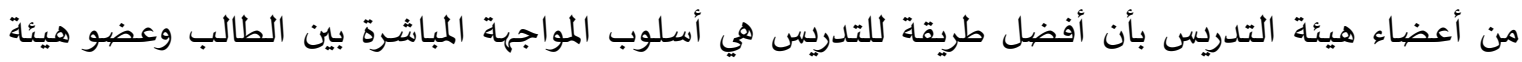
التدريس، افتقار بعض أعضاء هيئة التدريس إلى التمكن من مهارات التعامل مع تقنية المعلومات التدريسية.

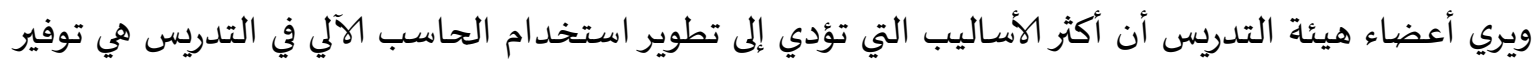

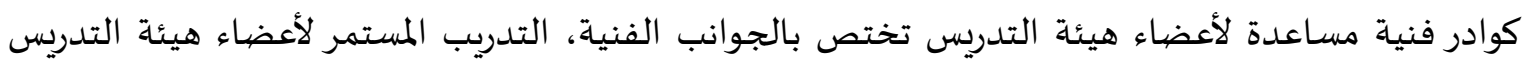

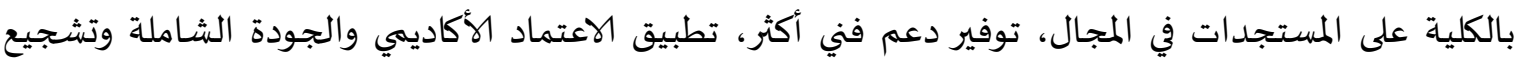

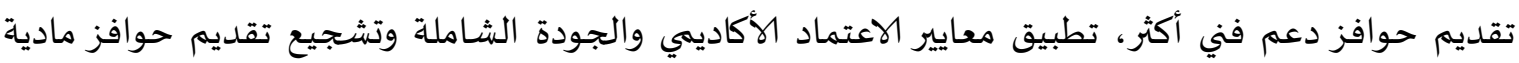


لأعضاء هيئة التدريس لاستخدام الحاسب الألي في التدريس ووجود اتجاه لدى أعضاء هيئة التدريس يمكن أن يقال عنه بشكل عام إنه متوسط نحو استخدام الحاسب الآلي في التدريس. وقامت الحافظي (2008) بإجراء دراسة هجفت إلى تحديد واقع استخدام أعضاء هيئة التدريس في جامعة

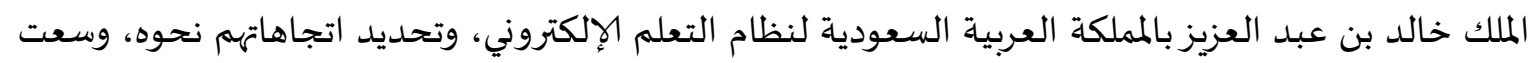

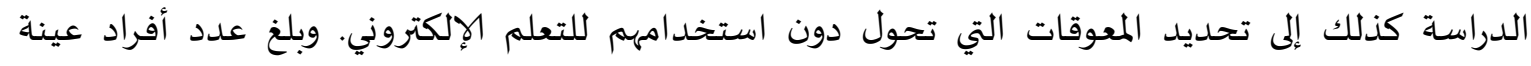

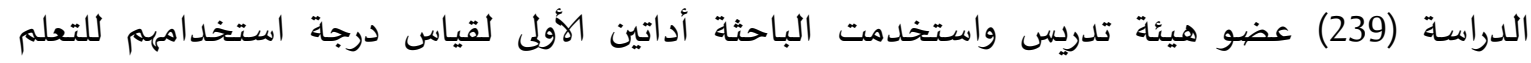

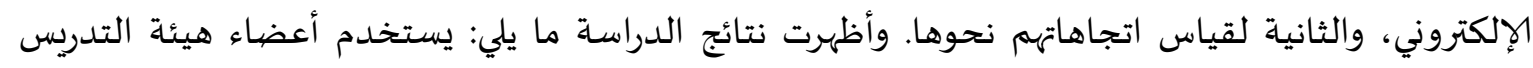

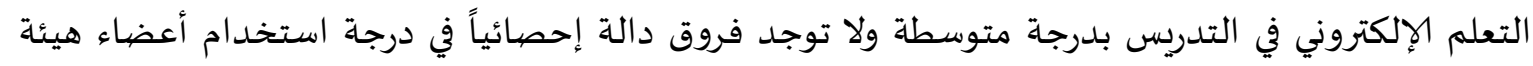

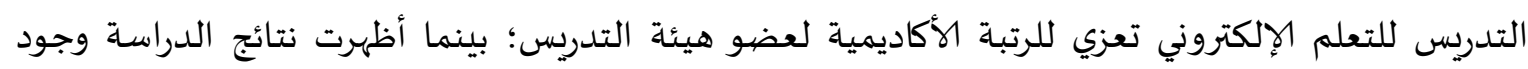
اتجاهات مرتفعة نحو استخدام التعلم الإكتروني في التدريس. وأجرى حشمت (2008) دراسة هدفت إلى معرفه فعالية التخاطب الصوتي والنصي بالفصول مرتفول الافتراضية

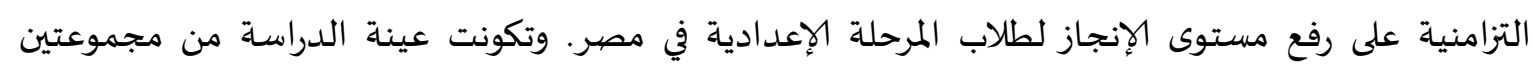

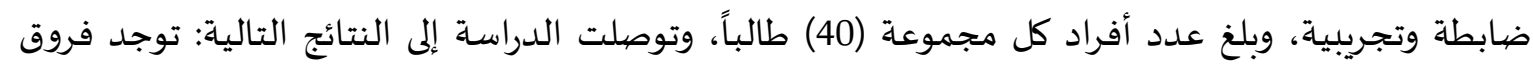

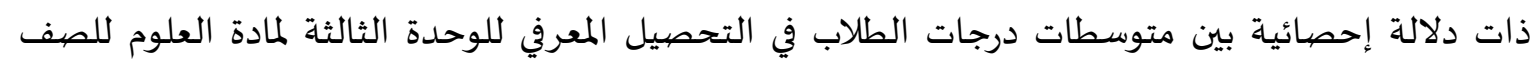

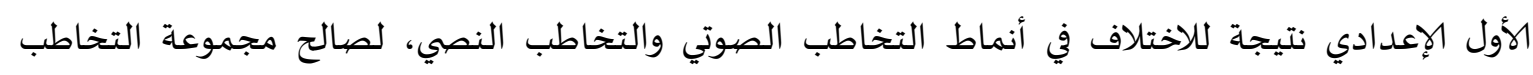

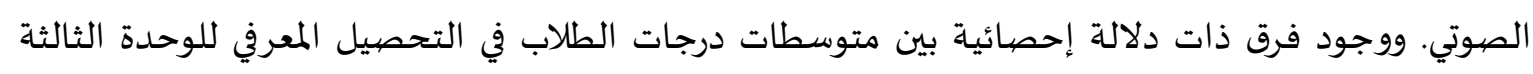

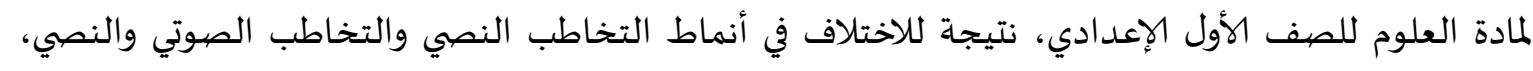

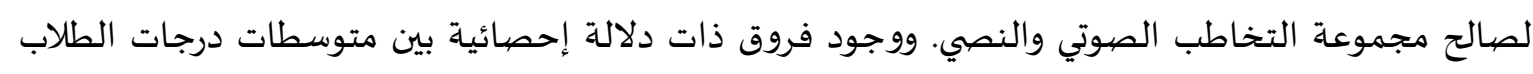

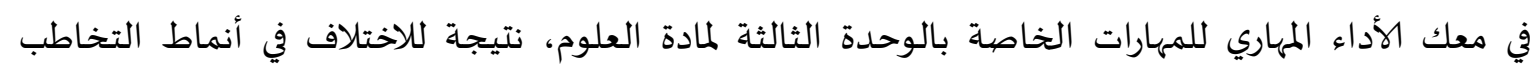

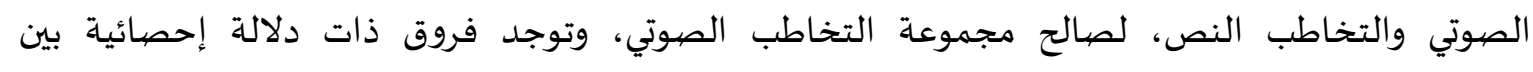

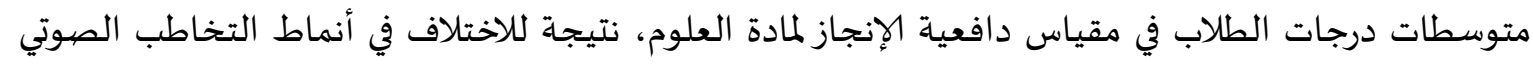

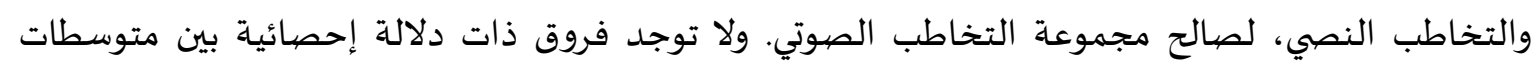

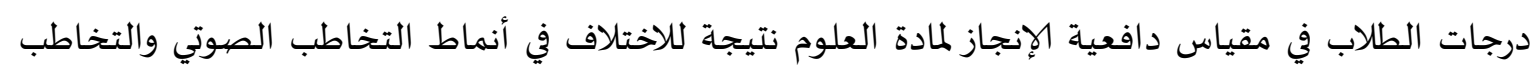
الصوتي والنصي، لصالح مجموعة التخاطب الصوتي.

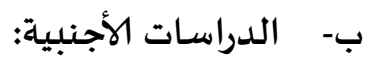

في دراسة كل من ماكبرين وجونز وشينغ (McBrien, Jone \& Cheng, 2009) والتي هدفت إلى البحث في أثر الثرات

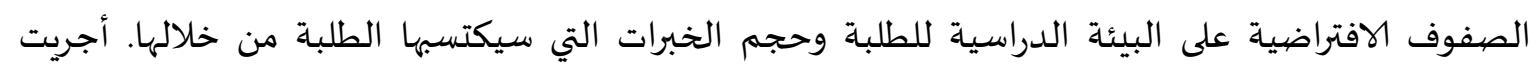

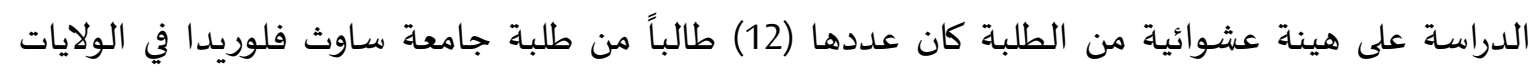

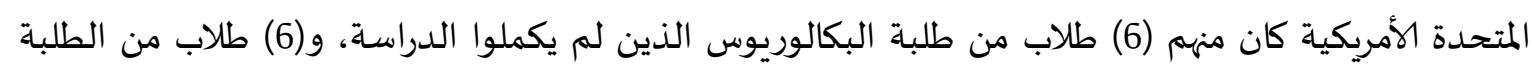
المتخرجين. استخدمت الدراسة أسلوب جع البيانات من الطلبة من خلال توزيع الاستبيانات على الماتى الطلبة.

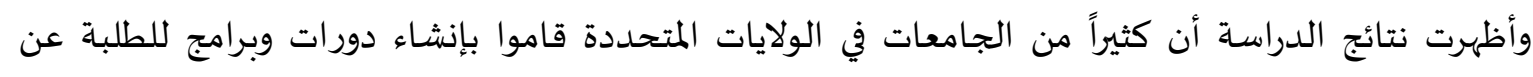

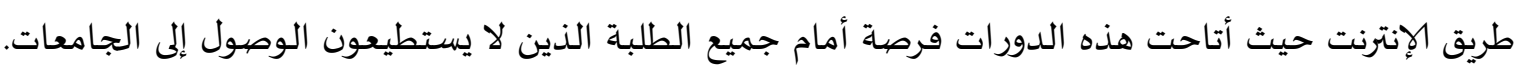

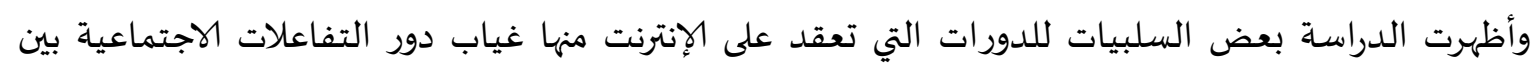


الطالب - المعلم والطالب-، وانعدام مشاركة الآراء والمواقف مع بعضهم البعض، وذلك يعود بسبب عدم التقائهم أثناء أخذ الدورات.

- وأجرى كل من أمبيكايراجا وايبس وشينغ وسيلر(Ambikairajah, Epps, Sheng \& Celler, 2008) دراسة

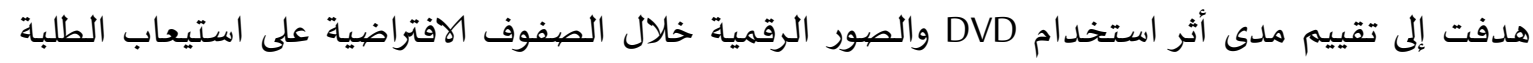

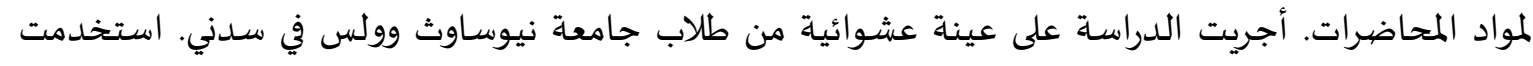
الدراسة أسلوب تقصي المعلومات من خلال محاضرات مسجلة مسبقاً على DVD لمشاركات الطلبة في الجامعادة.

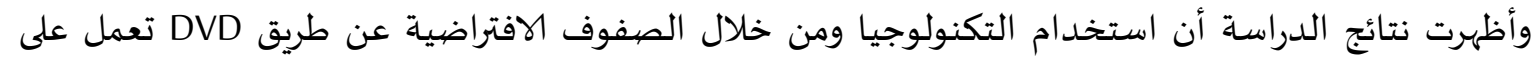

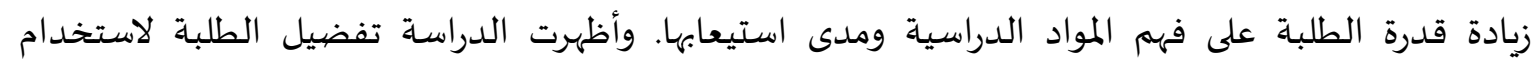

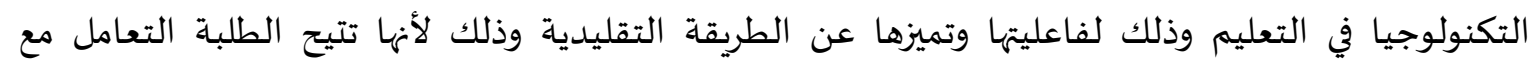

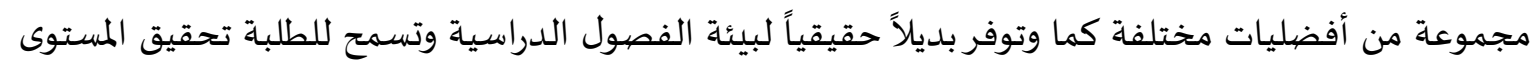

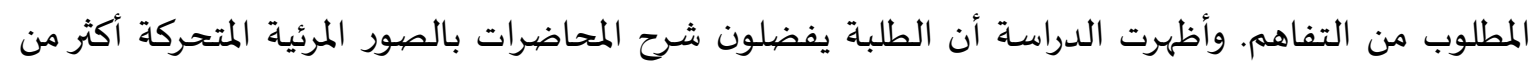
الاستماع فقط إلى شرح المعلم. وفاعلية استخدام الطالب للنظام.

المحور الثاني: دراسات ترتكز على استخدام بيئة التعلم بالاستقصياء.

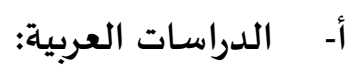

حيث نجد أن عددا من الباحثين اهتم بتدريب الطلاب على الاستقصاء العلمي وما يتضمنه من مهارات التفكير العلمي وعلميات العلم والاتجاه الإيجابي نحو العلم وخصائصهاه ومن بين هذه الدراسين الدراسات:

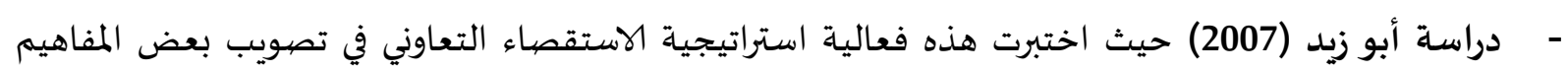

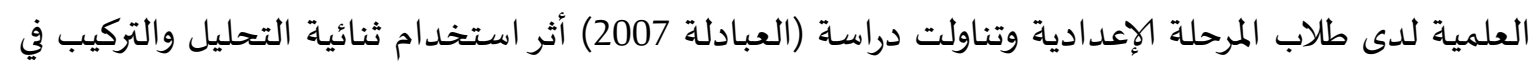

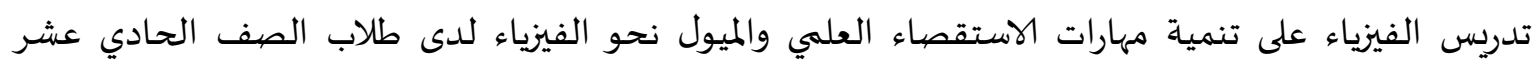

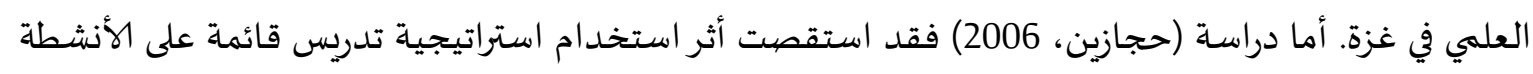

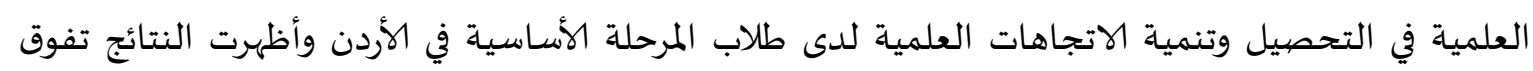
طلاب المجموعة التجريبية على طلاب المجموعاة الضابطة في التحصيل وفي تنمية الاتجاهات العبلهيل العلمياة.

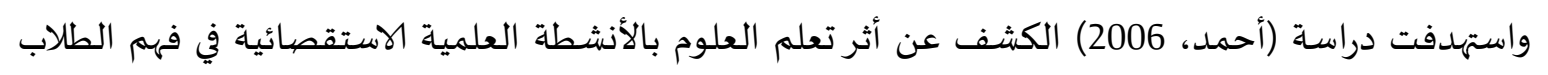

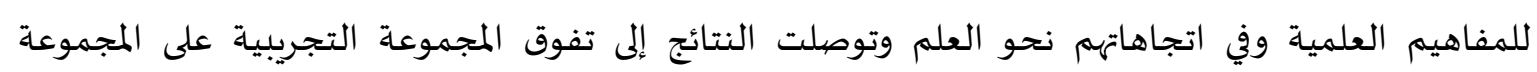
الضابطة في التحصيل وفي تنمية الاتجاهات العلمية.

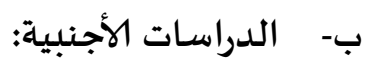

- أوضحت دراسة (Jackson, 2010) والتي أوضحت العلاقة المتبادلة بين طبيعة العلم وطبيعة الاستقصاء

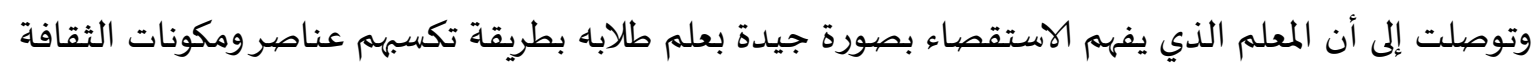

العلمية بشكل صحيح.

- أما دراسة الحالة التي أعدها (GAO, 2010) فقد كشفت عن أن معتقدات المعلمين حول الاستقصاء تؤثر على

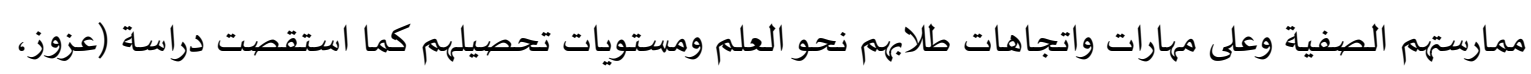

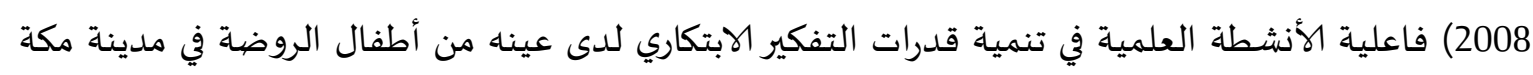
المكرمة، واستخدمت الباحثة اختيار أبراهام للتفكير الابتكاري عند أطفال الروضية. 
وقارنت دراسة (Berg, Anders, Bergendahl Christina \& Lundberg, 2003) بين استخدام طريقتي الاستقصاء المفتوح والاكتشاف في إجراء التجارب الكيميائية في المرحلة الجامعية وتوصلت إلى أن أسلوب ألماء الاستقصاء المفتوح أظهر نتيجة أفضل في التحصيل العلمي للطلاب.

التعليق على الدراسـات السابقة:

في ضوء عرض الدراسات السابقة لاحظت الباحثة أن منها دراسات تناولت استخدام الفصيول الافتراضية في

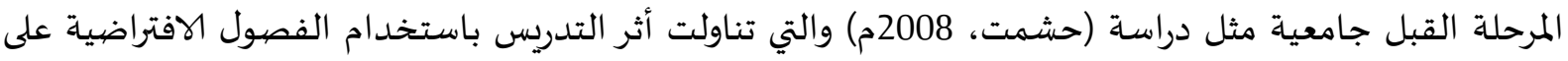

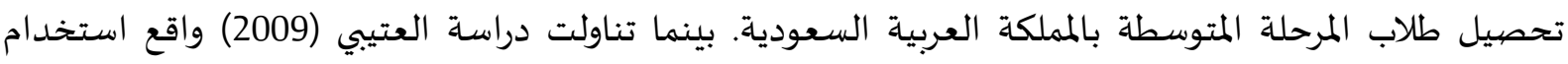

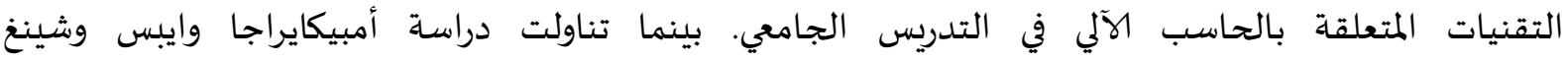
وسيلر(Ambikairajah, Epps, Sheng \& Celler, 2008) استخدام لعVDD والصور الرقمية خلال الصفوف الافتراضية

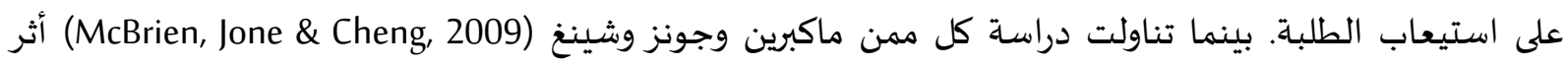
الصفوف الافتراضية على البيئة الدراسية للطلبة وحجم الخبرات التي سيكتسبها الطلبة من خلالها بينما تناولت

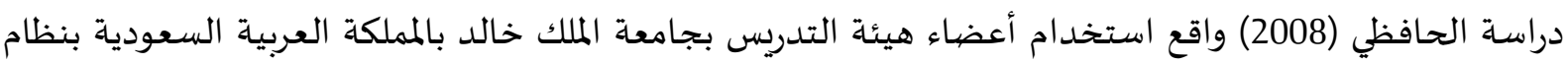
التعلم الإلكتروني، وتحديد اتجاهات نحوها

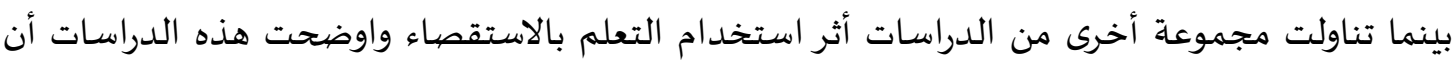

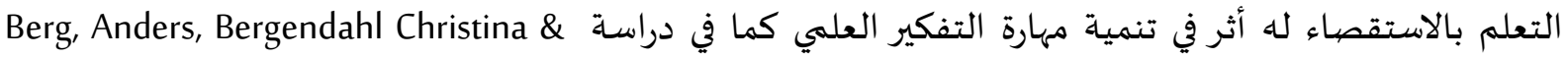

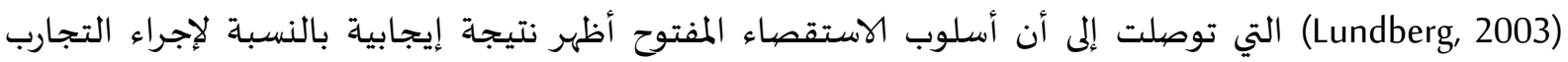

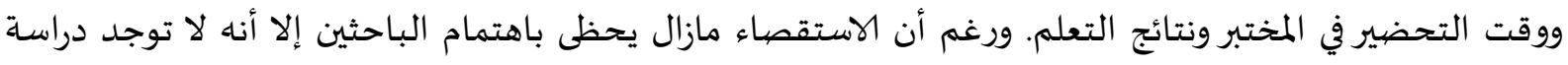

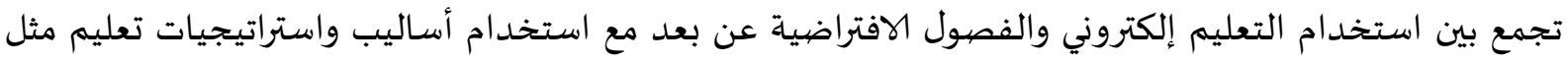

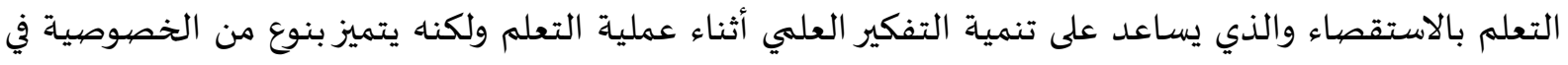
تناول اسلوب التدريس بالاستقصاء داخل الفصول الافتراضية، وهذا ما يتمتع به البحث الحالي وقد استفادت التهاء الباحثة من تلك الدراسات السابقة في اثراء الإطار النظري.

3- منهجية البحث وإجراءاته

منهجية البحث استخدمت الباحثة المنهج الوصفي وشبه التجبريبي لمناسبته لأغراض الدراسة.

مجتمع البحث: تكون مجتمع البحث من جميع أعضاء هيئة التدريس في جامعه الأمير سطام بن عبد العزيز بالخرج في

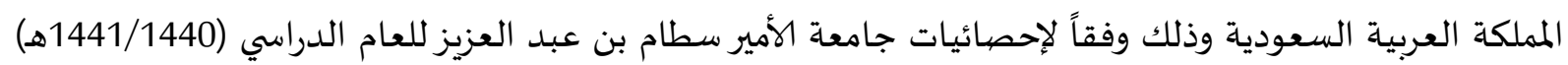
أثناء فتره تعليق الدراسة.

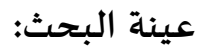
تكونت عينة الدراسة من (100) عضو من أعضاء هيئة التدريس من جامعة الأمير سطام بن عبد العزيز والتي تم اختيارهم بطريقة عشوائية طبقية. 
تعتمد الدراسة الحالية على استخدام الأدوات التالية:

1- استبانة قياس وعي أعضاء هيئة التدريس بنظام منصية التعلم الإلكتروني.

2- استبانة قياس اتجاهات أعضاء هيئة التدريس نحو بيئة التعلم بالاستقصياء.

3- المتغيرات الديموغرافية الإحصائية لاستخدام منصة التعليم الإلكتروني (بلاك بورد زووم) أو ما يسمى باهى

التدريس الطارئ عن بعد في ظل تفشي فيروس 19 - COVID أثناء فتره تعليق الدراسـاة.

الجانب للتطبيقي للبحث:

1- إعداد استبانة قياس وعي أعضاء التدريس بنظام البلاك بورد:

لإعداد استبانة قياس وعي أعضاء التدريس بمنصية البلاك بورد قامت الباحثة بمراجعاه الإطار النظري بناه

والدراسات السابقة التي تناولت موضوع استخدام تكنولوجيا التعليم في الجامعات مثل دراسة الحافظي (2008).

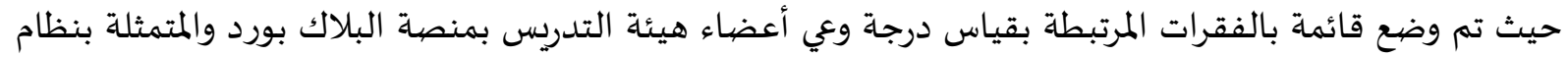
الفصول الافتراضية، تم صياغتها في شكل استبانة تكونت بصورتها الأولية من (30) فقرة. موزعاة في ثلاثة أبعاد هي: دور المعلم داخل منصية البلاك بورد مقارنه منصة البلاك بورد بالفصول الاعتيادية، عقبات استخدام منصية البلاك

وقد صممت الاستجابة على أداة الدراسة وفق مقياس رباعي التدرج كما يلي:

$$
\begin{aligned}
& \text { - - موافق بدرجه عالية (4) درجات } \\
& \text { - موافق بدرجة متوسطه (3) درجها. } \\
& \text { - - موافق بدرجاه منخفضية ولها (درجتان). } \\
& \text { - غير موافق ولها (درجه واحدة). }
\end{aligned}
$$

صدق استبانة قياس وعي أعضياء هيئة التدريس بمنصبة البلاك بورد تم عرض الاستبانة بصورتها الأولية على (10) محكما من ذوي الاختصاص فئه في مجالات التعلم الإلكتروني وتكنولوجيا التعليم والمناهج وطرق التدريس في جمهورية مصر العربية والمملكة العربية السعودية، وقد طلب منهم تحديد مدى ملاءمة الفقرات الواردة في الاستبانة ومدى شموليتها لقياس وعي أعضاء هيئة التدريس بمنصية التعلم

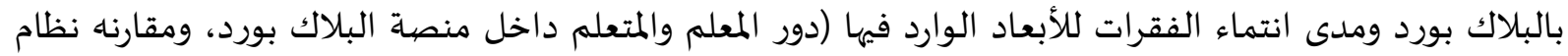
البلاك بورد والفصول الافتراضية بالفصول المعتادة، وعقبات استخدم منصة البلاك بورد) ومدى وضوح الفيكاء الفقرات وسلامتها لغوية.

ثبات استبانة قياس وعي أعضاء هيئة التدريس بمنصية البلاك بورد للتأكد من ثبات الاستبانة تم حساب معامل الاتساق الداخلي للفقرات باستخدام معينه معادلة (كرونباخ ألفا) لكل من أبعاد الاستبانة والدرجة الكلية للاستبانة قد تراوحت قيمه معامل الثبات للأبعاد الفرعية ما بين (0.74)

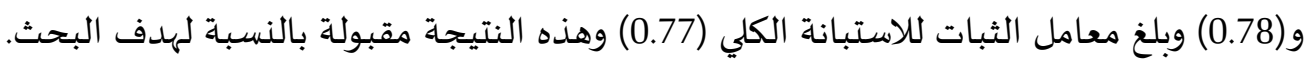

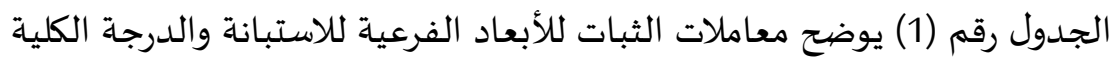


جدول (1) معاملات ثبات الاتساق الداخلي للأبعاد الأربعة للاستبانة

\begin{tabular}{|c|c|}
\hline قيماه معامل & البعد \\
\hline 0.74 & أسـاسيات منصة التعلم الإلكتروني (البلاك بورد) وأهميتها. \\
\hline 0.78 & دور الطالب وعضو هيئة التدريس داخل منصة التعلم الإلكتروني (البلاك بورد) \\
\hline 0.77 & مقارنه بين منصة التعلم الإكتروني (البلاك بورد) والتدريس التقليدي \\
\hline 0.77 & الصعوبات التي واجهت عضو هيئة التدريس في استخدام منصة التعلم الإلكتروني (البلاك \\
\hline 0.77 & 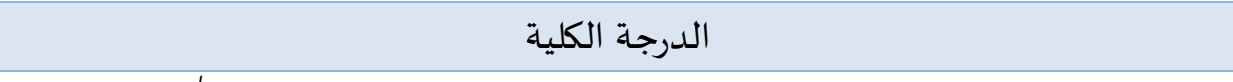 \\
\hline
\end{tabular}

بالنسبة لطريقة الاجابة على الاستبانة فكانت عن طريق وضع اشـارة (ل/) في المربع الذي ينتمي لدرجة اختيار الفقرة واشتملت الاستبانة على الاتجاهات الاتية:

(موافق بدرجه عالية =4)، (موافق بدرجاه متوسطة =3)، (موافق بدرجة متدنية الأنية =2)، (غير موافق =1) وتم حساب اوزان استبانة الفقرات على النحو التالي: - الفقرة التي يتراوح متوسطها الحسابي بين (3.02- 4) تعني أن درجه وعي أعضياء هيئة التدريس بمنصية التعلم الإلكتروني (البلاك بورد) مرتفعة. - الفقرة التي يتراوح متوسطها الحسابي بين (2.02- 3) تعني أن درجه وعي أعضياء هيئة التدريس بمنصية التعلم الإلكتروني (البلاك بورد) متوسطة. - الفقرة التي يتراوح متوسطها الحسابي بين (1- 2) تعني أن درجه وعي أعضاء هيئة التدريس بمنصية التعلم الإلكتروني (البلاك بورد) منخفضية. 2- استبانة قياس اتجاهات أعضاء هيئة التدريس نحو بيئة التعلم بالاستقصياء.

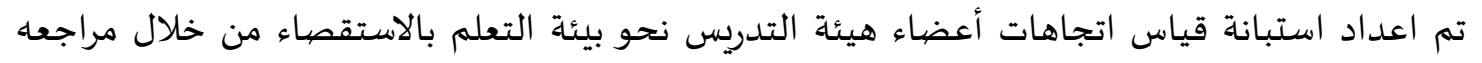

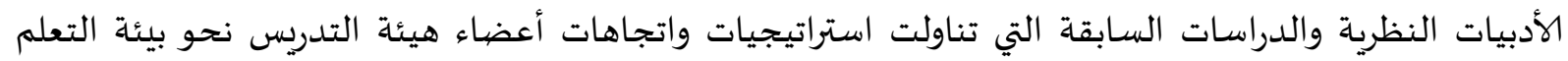
بالاستقصاء، حيث تم وضع قائمة تتضمن فقرات لقياس اتجاهات أعضاء هيئة التدريس نحو بيئة التعلم بالاستقصاء، ثم صياغتها على شكل استبانة تكونت بصورتها الأولية من (20) فقرة موزعاه على النحو التالي:

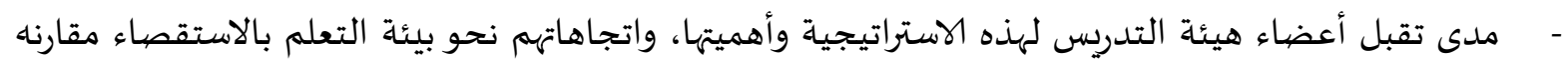

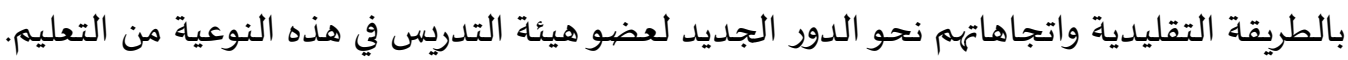
- وقد صمت الاستجابة وفق مقياس رباعي التدرج كما يلي:

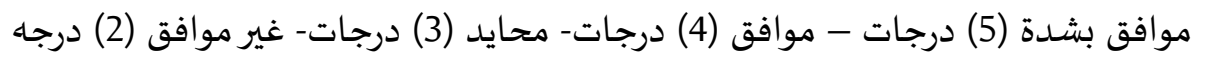
صدق استبانة قياس اتجاهات أعضاء هيئة التدريس نحو بيئة التعلم بالاستقصاء.

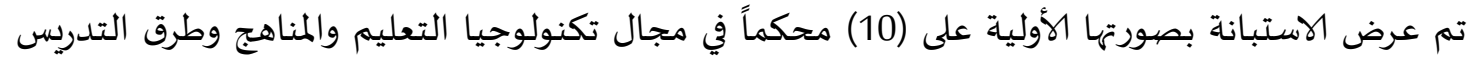

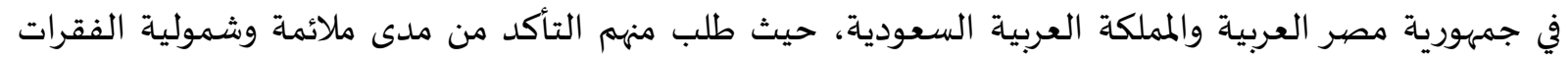

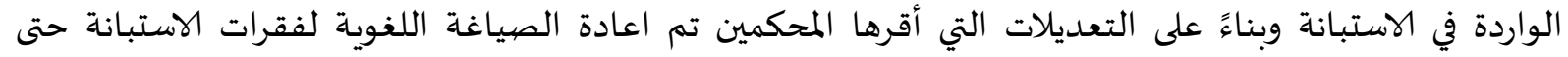

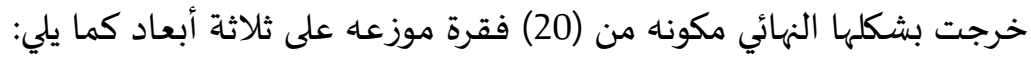

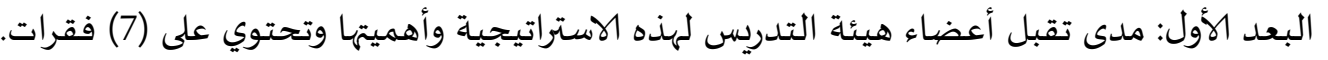


البعد الثاني: اتجاهات أعضاء هيئة التدريس نحو بيئة التعلم بالاستقصاء مقارنه بالطريقة التقليدية تحتوى على (7) فقرات.

البعد الثالث: اتجاهات أعضاء هيئة التدريس نحو الدرور الجديد لعضو هيئة التدريس في هذه النوعية من

$$
\text { التعليم وتحتوي على (6) فقرات. }
$$

ثبات استبانة قياس اتجاهات أعضياء هيئة التدريس نحو بيئة التعلم بالاستقصاء.

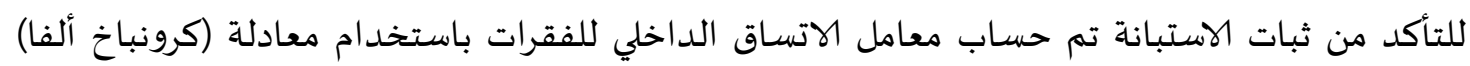

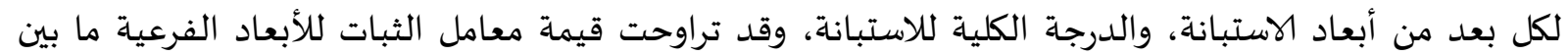

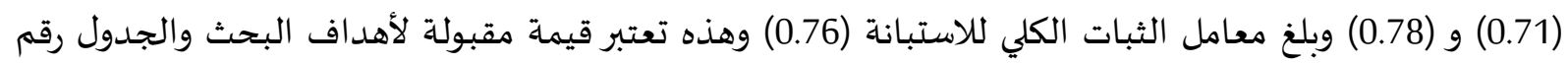

$$
\text { (2) يوضح معاملات الثبات للأبعاد الفرعية للاستبانة والدرجة الكلية. }
$$

\begin{tabular}{|c|c|}
\hline قيماه معامل & البعد \\
\hline 0.78 & مدى تقبل أعضاء هيئة التدريس لهذه الاستراتيجية وأهميتها \\
\hline 0.71 & اتجاهات أعضاء هيئة التدريس نحو بيئة التعلم بالاستقصياء مقارنها بالطريقة التقليدياة. \\
\hline 0.76 & اتجاهات أعضاء هيئة التدريس نحو الدرور الجديد لعضو هيئة التدريس في هذه النوعية من \\
\hline 0.76 & 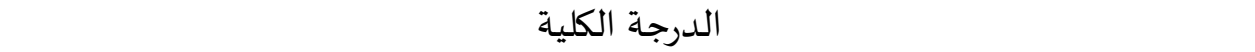 \\
\hline
\end{tabular}

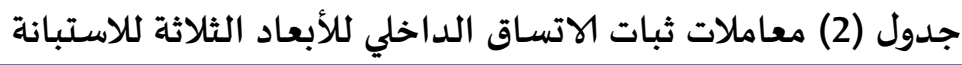

بالنسبة لطريقة الاجابة على الاستبانة فكانت عن طريق وضع اشـارة (لل) في المربع الذي ينتمي لدرجة اختيار

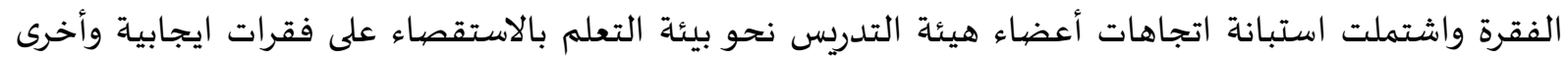
سالبة الاتجاه على النحو التالي: حيث أخذت الفقرات الموجبة الاتجاه العلامات التالية: موافق بشدة (5) درجات - موافق (4) درجات- محايد (3) درجات- غير موافق (2) درجهات. أما الفقرات سالبة الاتجاه فأخذت العلامات التالية: موافق بشدة (2) درجات - موافق (3) درجات- محايد (4) درجات- غير موافق (5) درجاه. وتم حساب اوزان استبانة الفقرات على النحو التالي: 1. الفقرة التي يتراوح متوسطها الحسابي بين (3.67- 5) تعني أن درجه اتجاهات أعضاء هيئة التدريس نحو بيئة التعلم بالاستقصاء مرتفعة. 2. الفقرة التي يتراوح متوسطها الحسابي بين (2.33- 3.65) تعني أن درجه اتجاهات أعضاء هيئة التدريس نحو بيئة التعلم بالاستقصاء متوسطة. 3. الفقرة التي يتراوح متوسطها الحسابي بين (2.35-1.00) تعني أن درجه اتجاهات أعضاء هيئة التدريس نحو

بيئة التعلم بالاستقصاء منخفضية. 3- المتغيرات الديموغرافية الإحصائية لاستخدام منصية التعليم الإلكتروني في ظل تفشي فيروس 19 - COVID

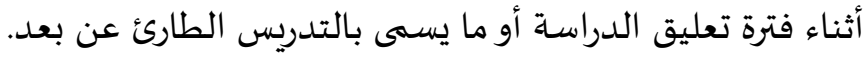


وفي هذا المتغير تم الرجوع إلى الإحصائيات التي استخدمتها جامعة الأمير سطام خلال فترة تعليق الدراسة

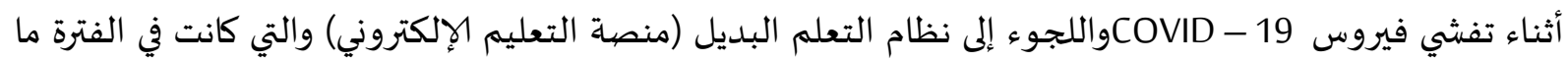
بين الثلاثاء 1441/7/15هـ الموافق 2020/3/10م إلى الخميس 1441/9/21هـ الموافق 2020/5/14هـ وهى نهاية فترة

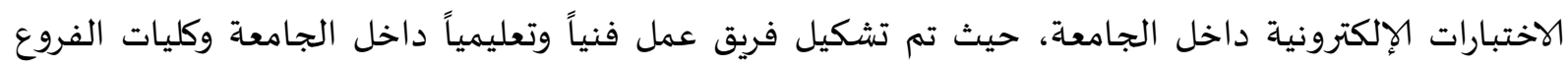

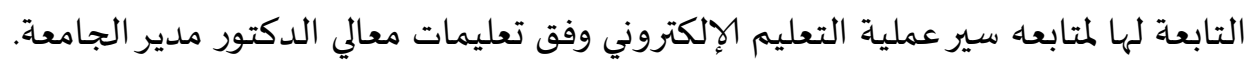

$$
\text { اجراءات البحث: }
$$

1. الاطلاع على الأدبيات والدراسات السابقة التي تفيد في إعداد أدوات البحث.

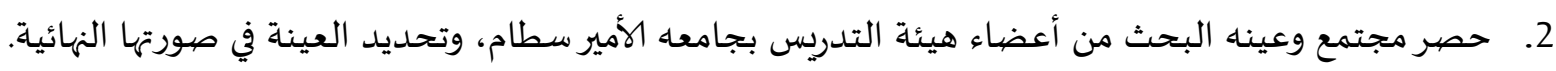

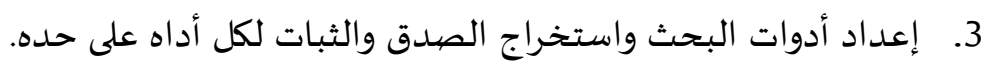

4. تطبيق استبانة قياس وعي أعضاء هيئة التدريس بنظام قياس وعي أعضاء هيئة التدريس بنظام منصية التعلم

الإلكتروني.

5. تطبيق استبانة قياس اتجاهات أعضاء هيئة التدريس نحو بيئة التعلم بالاستقصياء.

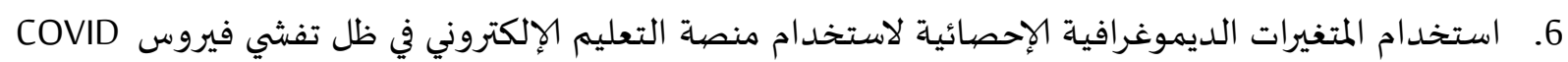

19 - داخل جامعه الأمير سطام.

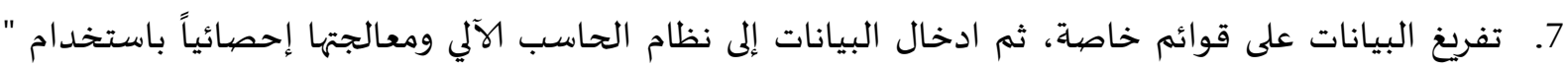
الرزمة الإحصائية للعلوم الاجتماعية" (SPSS).

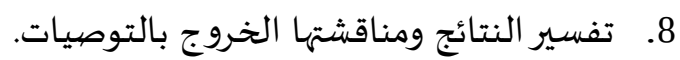

4- أهم النتائج ومناقشتها: للإجابة على السؤالين الأول والثاني وتتعلق بدرجة وعي أعضياء هيئة التدريس بمنصية التعلم الإلكتروني

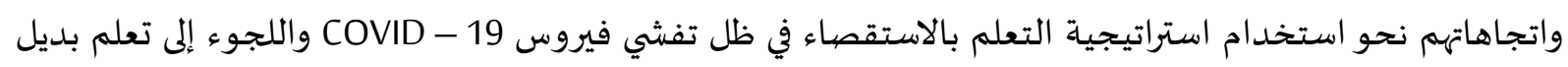
أثناء فترة تعليق الدراسـة، تم استخدام المتوسطات والانحرافات المعيارية والمتغيرات الديموغرافية الإحصائية.

نتائج البحث:

النتائج المتعلقة بالإجابة عن السؤال الأول والذي ينص على : "ما درجة وعي أعضاء هيئة التدريس

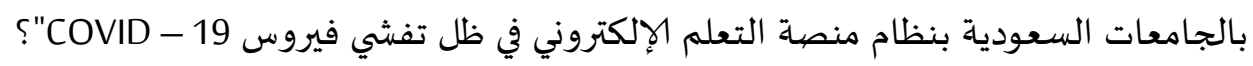
ولإجابة على هذا السؤال تم استخدام المتغيرات الديموغرافية الإحصائية داخل جامعام الماده الأمير سطام أثناء فترة تعليق الدراسة أو ما يطلق عليه التدريس الطارئ عن بعد، حيث وجد مالئ ما يلي:

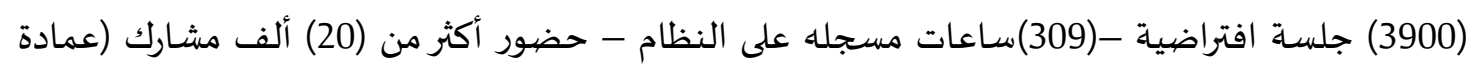

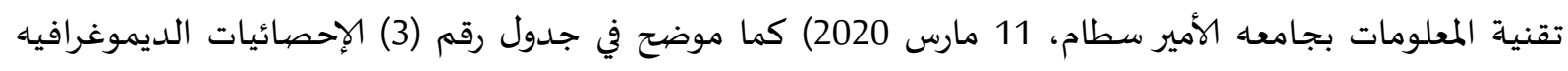
داخل جامعاء الأمير سطام أثناء فترة تعليق الدراسة واستخدام منصية التعلم الإكتروني 
جدول (3) إحصائيات بيئة استخدام التعلم الإلكتروني في ظل تفشي فيروس 19 - COVID ودرجه وعي أعضياء هيئة التدريس به داخل جامعه الأمير سطام

\begin{tabular}{|c|c|c|c|c|c|c|c|}
\hline \multirow{2}{*}{ تم استعراضهات الملفات } & \multirow{2}{*}{ المداش لوحات } & \multicolumn{3}{|c|}{ عدد التقييمات Assessments } & \multirow{2}{*}{ 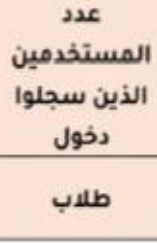 } & \multirow{2}{*}{ التاريخ } & \multirow{2}{*}{ اليوم } \\
\hline & & الاختبارات & الإجباتة & الواجبات & & & \\
\hline 5,920 & 4 & 750 & 277 & 2.265 & 20.570 & $22 / 3$ & الأحد \\
\hline 5.979 & 5 & 792 & 302 & 2,455 & 20,980 & $23 / 3$ & الاثنين \\
\hline 5,949 & 4 & 758 & 301 & 2.588 & 21,103 & $24 / 3$ & الثلاء \\
\hline 5,470 & 7 & 890 & 299 & 2730 & 20.999 & $25 / 3$ & الأربعاء \\
\hline 4.627 & 6 & 849 & 319 & 2703 & 19,125 & $26 / 3$ & الخميس \\
\hline 27,945 & 26 & 4039 & 1498 & 12741 & $102 \mathrm{~m}$ & & الإج \\
\hline
\end{tabular}

القيمة الأعلىه

$\Omega$

رسم بياني (1) إحصيائيات بيئة استخدام التعلم الإكتروني في ظل تفشي فيروس COVID - 19 ودرجه وعي أعضاء هيئة التدردس باه داخل جامعاه الأمير سطام

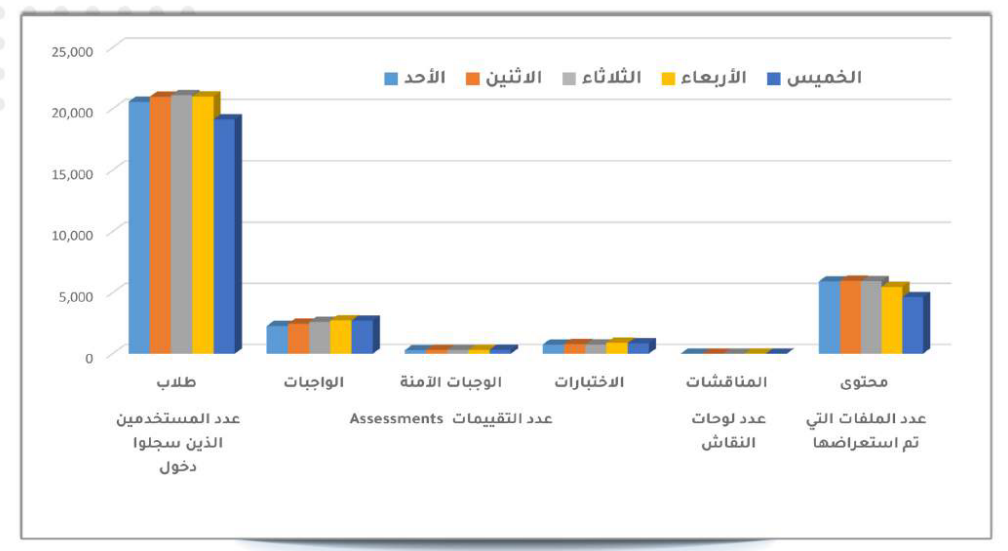

من خلال العرض السـابق الموضح في جدول رقم (r) والرسم البياني رقم (1) أن هناك درجه من الوعي من

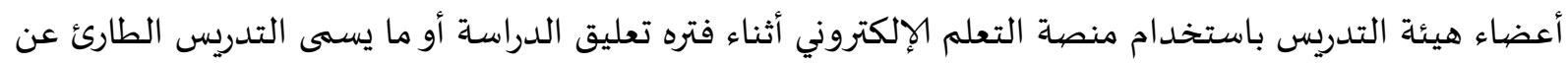

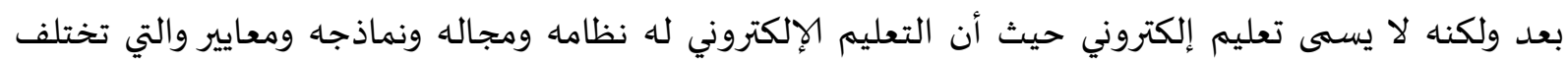

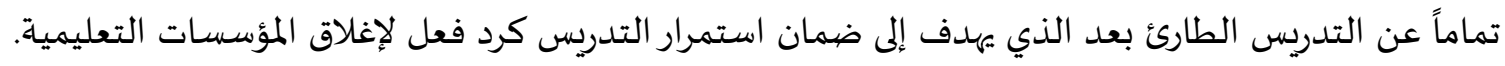


جدول (4) اجمالي استخدام الفصول الافتراضية داخل منصة التعلم الإكتروني من قبل عضو هيئة التدريس بالجامعة.

\begin{tabular}{|c|c|c|c|c|c|}
\hline \multirow{2}{*}{ أكبر عدد من الملسات } & (في جميع الجلساضرين الفريدين) & عميع الجلسات الحرين في & لجميع الجلسات الإجمالية & الجلسات التي تم إنمالي & \multirow{2}{*}{ التاريخ } \\
\hline & $\begin{array}{l}\text { Number of unique } \\
\text { attendees (in all sessions) }\end{array}$ & $\begin{array}{c}\text { Number of } \\
\text { attendees (in all } \\
\text { sessions) }\end{array}$ & $\begin{array}{l}\text { Total duration } \\
\text { of all sessions }\end{array}$ & $\begin{array}{l}\text { Number of total } \\
\text { sessions created }\end{array}$ & \\
\hline 950 & 18624 & 38184 & $4585: 20: 50$ & 1292 & $22 / 3$ \\
\hline 996 & 19901 & 40643 & $4752: 24: 27$ & 1401 & $23 / 3$ \\
\hline 968 & 19967 & 40364 & $4717: 16: 15$ & 1366 & $24 / 3$ \\
\hline 951 & 19151 & 38375 & $4411: 56: 40$ & 1182 & $25 / 3$ \\
\hline 773 & 14080 & 25704 & $3166: 58: 42$ & 967 & $26 / 3$ \\
\hline 4638 & 91723 & 183270 & 21627:56:54 & 6208 & الإجمالي \\
\hline
\end{tabular}

القيمة الأعلىه

رسم بياني (2) اجمالي استخدام الفصول الافتراضية داخل منصية التعلم الإكتروني من قبل عضو هيئة التدريس بالجامعة

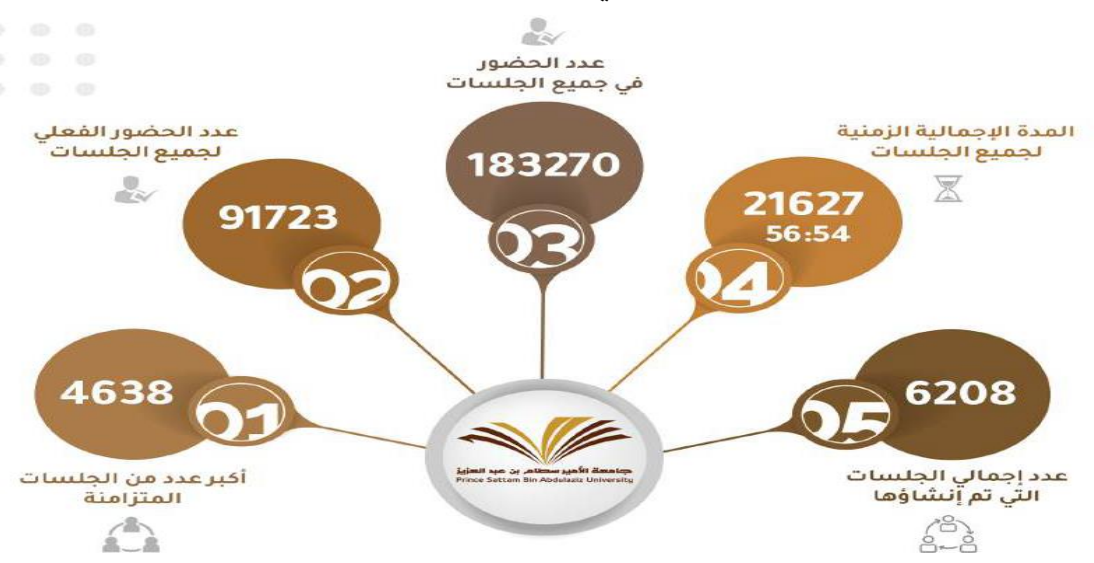

من خلال العرض السابق الموضح في جدول رقم (ع) والرسم البياني رقم (Y) أن هناك درجه من الوعي من

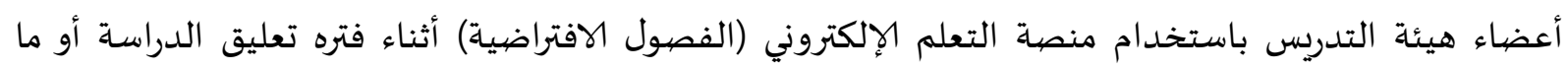

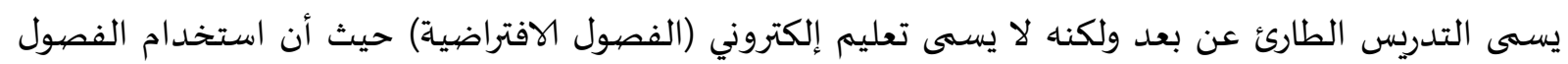
الافتراضية يحتاج إلى تخطيط وتصميم تعليمي دقيق يتم وفق نموذج ممنهج، ويبنى عليه قرارات تؤثر في جودة

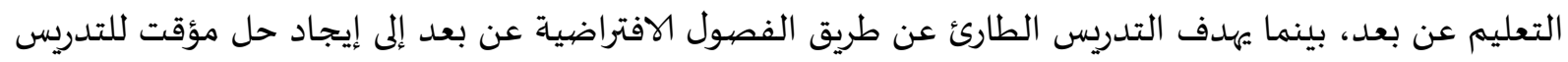

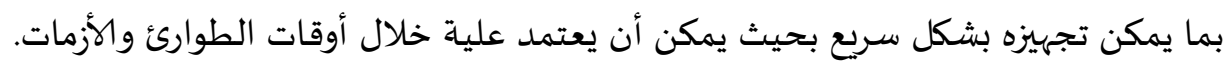


جدول (5) اجمالي عدد الدورات التدريبية التي حصل عليها عضو هيئة التدريس أثناء فترة تعليق الدراس

\begin{tabular}{|c|c|c|}
\hline عدد الحضور & عنوان الدورة & اليوم والتاريخ / الوقت \\
\hline 21 & ألافتاسيات البلاك بورد & الأحد 22 مارس اللى 12020 \\
\hline 35 & 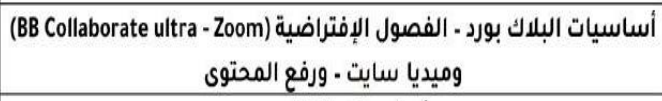 & الاثنين 23 مارس 2020 من إلى 12م \\
\hline 55 & $\begin{array}{c}\text { أساسيات البلاك بورد } \\
\text { الافتبارات والواجبات } \\
\end{array}$ & الثلاثاء 24 مارس 10 10 إلى 2020 \\
\hline 40 & أساسيات البلاك بورد & الأربعاء 25 مارس 2020 الى 120م \\
\hline 41 & $\begin{array}{l}\text { أساسيات البلاك بورد - الفصول الإفتراضية } \\
\text { (BB Collaborate ultra - Zoom) }\end{array}$ & الخميس 26 مارس 2020 من 10ص إلى 12م \\
\hline 192 & الإجمالي & \\
\hline
\end{tabular}

رسم بياني(3) يوضيح اجمالي الزيارات اليومية لبوابه التعلم الإكتروني من قبل عضو هيئة التدريس داخل جامعه الأمير سطام

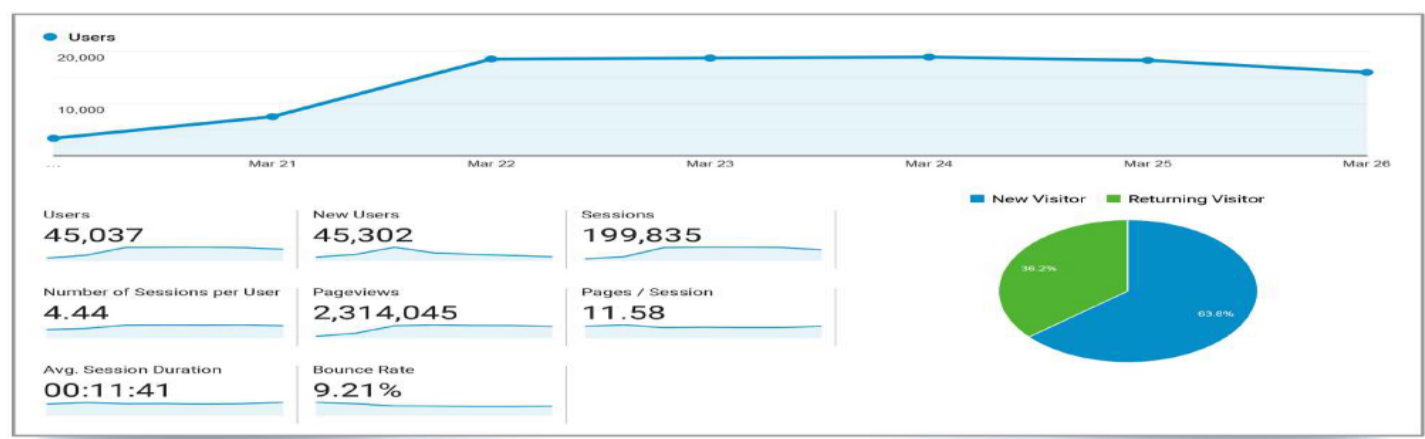

(التقرير الأسبوعي الثالث عن سير التعليم الإكتروني بجامعه الأمير سطام، 22-26 مارس 2020م)

من خلال العرض السابق الموضح في جدول رقم (0) والرسم البياني رقم (r) أن هناك درجاء من الوعي من

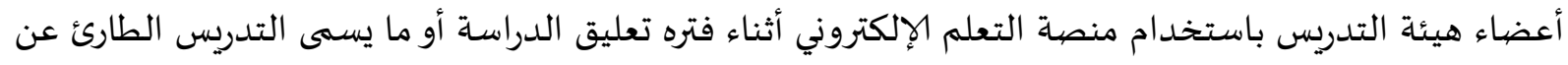
بعد ولكنه لا يسهى تعليم إلكتروني حيث أنه يحتاج تصميم دورات تدريبية باستخدام التعليم الإلكتروني على أبعاد

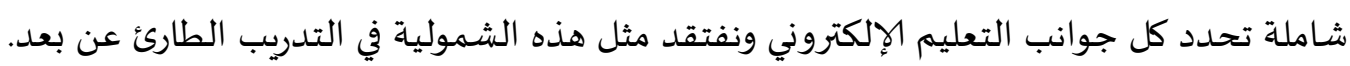

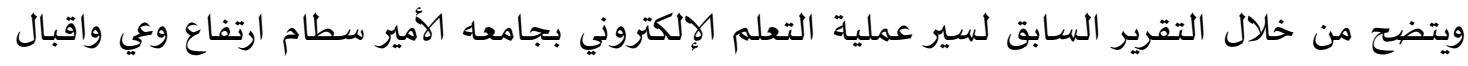

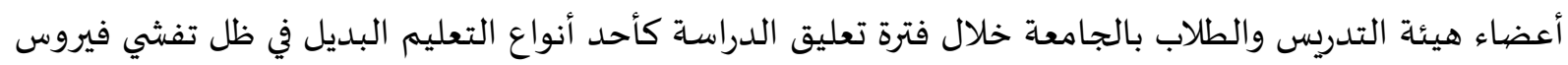

..COVID- 19

ويبين الجدول (6) درجة وعي أعضاء هيئة التدريس في جامعه الأمير سطام بمنصة التعلم الإلكتروني "

جدول (6) المتوسط الحسابي والانحراف المعياري لدرجة وعي أعضاء هيئة التدريس بمنصة التعلم الإلكتروني "

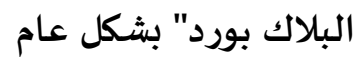

\begin{tabular}{|c|c|c|c|c|}
\hline درجة الوعي & المعياري & الحستوسط & 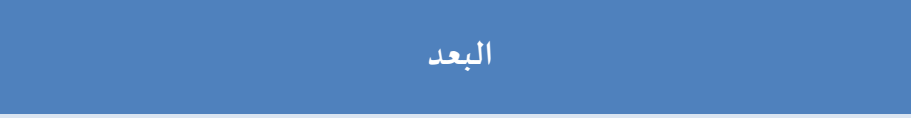 & 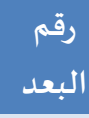 \\
\hline 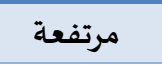 & 0,33 & 3,44 & أساسيات منصهة التعلم الإكتروني (البلاك بورد) وأهميتها. & 1 \\
\hline مرتفعة & 0,40 & 3,45 & دور الطالب وعضو هيئة التدريس داخل منصية التعلم الإلكتروني (البلاك & 2 \\
\hline
\end{tabular}


المجلة العربية للطوم ونشر الأبحاث ـ مجلة العلوم التريوية والنفسية ـ المجلد الرابع ـ العدد الساس والأربعون ـ ديسمبر 2020م

\begin{tabular}{|c|c|c|c|c|}
\hline درجة الوعي & المعباري & المتوسط & 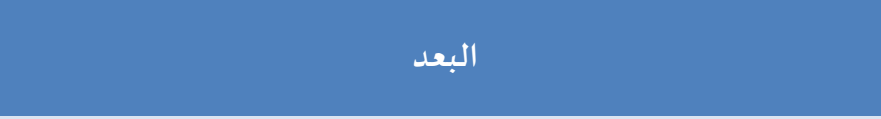 & 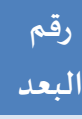 \\
\hline 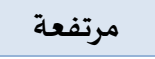 & 0,42 & 3,37 & مقارنه بين منصهة التعلم الإكتروني (البلاك بورد) والتدريس التقليدي & 3 \\
\hline 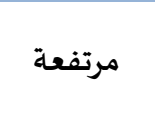 & 0,31 & 3,38 & 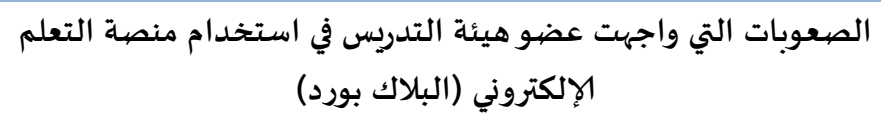 & 4 \\
\hline 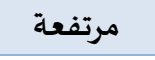 & 0,24 & 3,41 & الكلي (الاستبانة) & \\
\hline
\end{tabular}

يظهر الجدول (6) أن درجة وعي أعضاء هيئة التدريس في جامعاه الأمير سطام بن عبد العزيز بمنصية التعلم

الإلكتروني " البلاك بورد) على الاستبانة الكلية كانت مرتفعة، بمتوسط حسابي (3,41) وانحراف معياري (0,24).

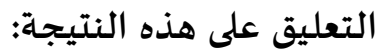

وترجع هذه النتيجة إلى أن درجة وعي أعضاء هيئة التدريس كانت مرتفعة وذلك لما تتميز باه تقنية التعليم

الإلكتروني من وجود عضو هيئة التدريس على الشبكة أثناء تعلم الطلاب وهذا يؤدي إلى الاتصال المباشر ما بين

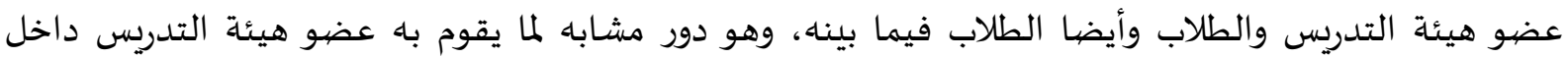
القاعات الدراسية. وبالتالي تكون منصة التعلم الإلكتروني شاملة على ايجابيات التعلم الصفي العادي والتعلم الفردي باستخدام الحاسب.

وترى الباحثة أن ما تقدمه منصة التعلم الإكتروني من امكانية التخاطب الصوتي، والكتابة، تمكن عضو

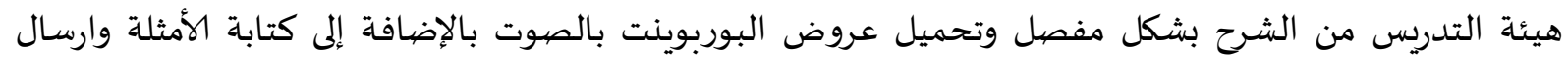

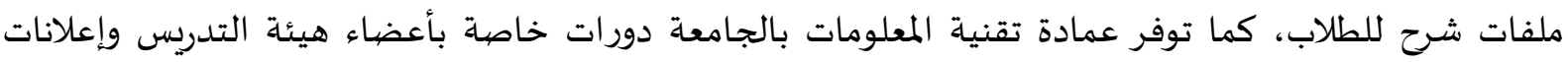
دورية وورش عمل مما يؤدي إلى رفع وعيهم بأدوار كل من عضيو هيئة التدريس والطلاب بهذه المعات المنصة.

\section{النتائج المتعلقة بالإجابة عن السؤال الثاني:}

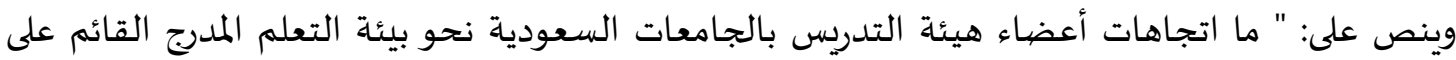

التعلم بالاستقصاء؟؟

للإجابة عن هذا السؤال تم احتساب المتوسط الحسابي والانحراف المعياري لاتجاهات أعضاء هيئة

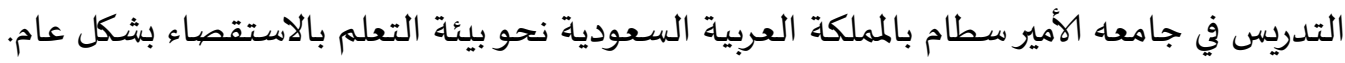

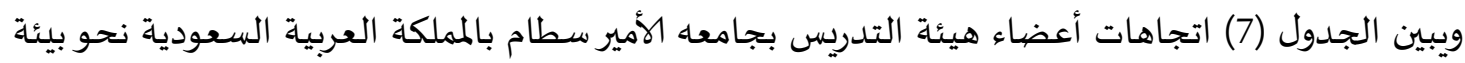

التعلم بالاستقصياء بشكل عام.

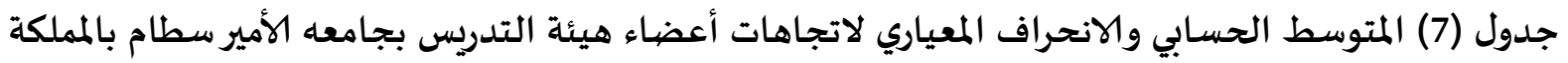
العربية السعودية نحو بيئة التعلم بالاستقصاء

\begin{tabular}{|c|c|c|c|c|}
\hline 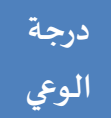 & المعياري & الحتوسط الحسابي & 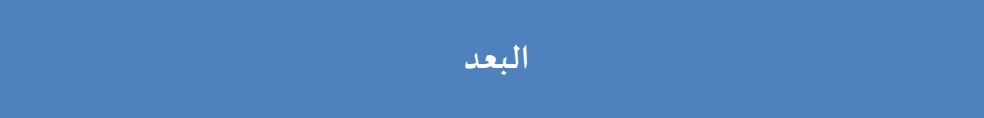 & 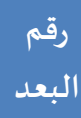 \\
\hline 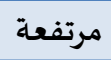 & 0,42 & 3,82 & مدى تقبل أعضاء هيئة التدريس لهذه الاستراتيجية وأهميتها & 1 \\
\hline متوسطة & 0,58 & 3,49 & اتجاهات أعضاء هيئة التدريس نحو بيئة التعلم بالاستقصهاء مقارنه بالطريقة & 2 \\
\hline 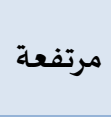 & 0,51 & 3,69 & اتجاهات أعضاء هيئة التدريس نحو الدرور الجديد لعضيو هيئة التدريس في هذه & 3 \\
\hline مرتفعة & 0,40 & 3,65 & الكلي (الاستبانة) & \\
\hline
\end{tabular}


يظهر الجدول (7) أن اتجاهات أعضاء هيئة التدريس في جامعه الأمير سطام بالمملكة العربية السعودية نحو

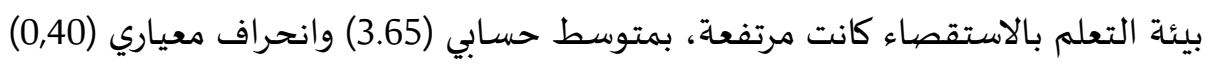

\section{التعليق على هذه النتيجة}

وترجع هذه النتيجة إلى أن درجة اتجاهات أعضاء هيئة التدريس في جامعاه الأمير سطام بالمملكة العربية

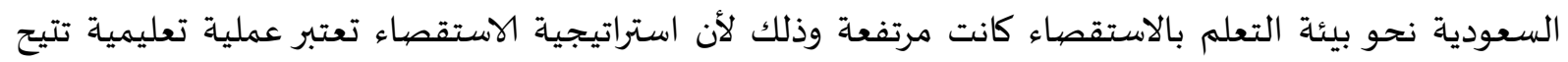

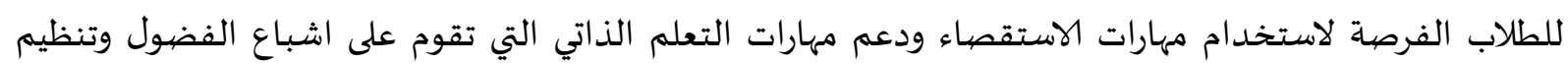

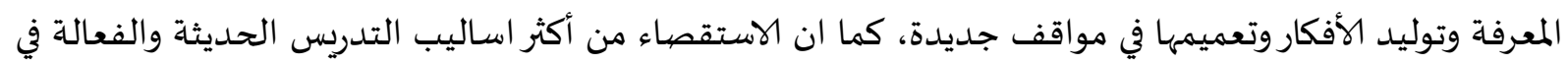

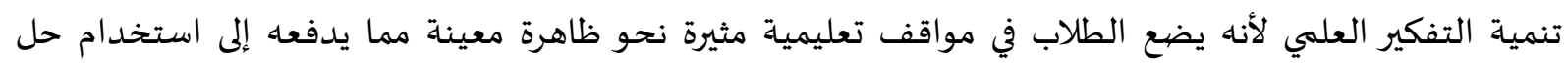

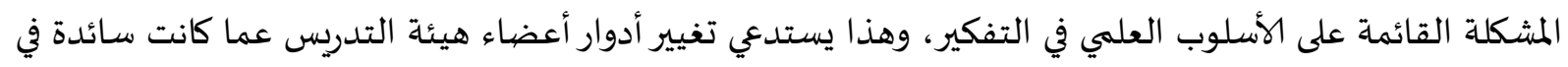
السابق حيث أن أصبح عضو هيئة التدريس يقوم بمهام مختلفة أثناء استخدام بيئة التعلم بالاستقصاء ومنها

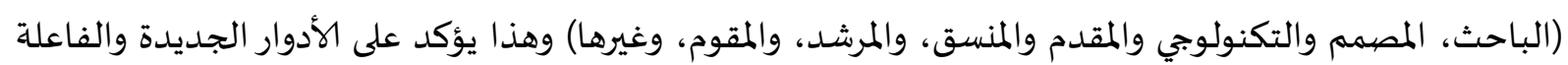
لعضو هيئة تدرس واتجاهـ نجو بيئة التعلم بالاستقصاء.

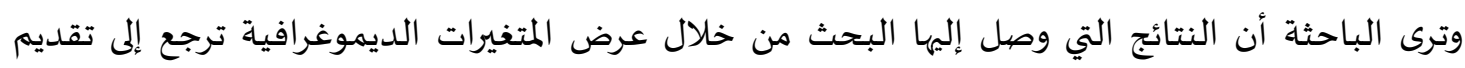

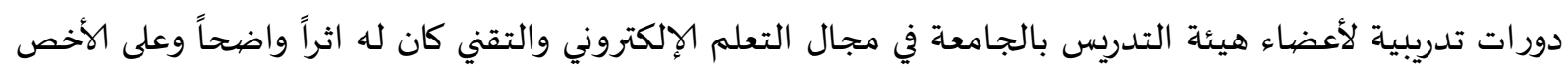

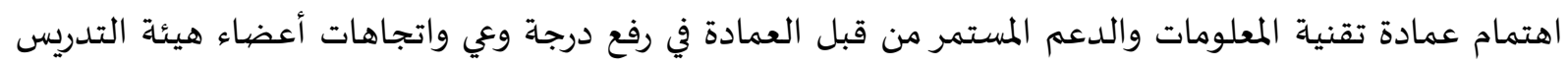
بالجامعة نحو منصية التعلم الإلكتروني.

$$
\text { التوصيات والمقترحات. }
$$

1. وضع معايير للتعلم عبر الإنترنت (البلاك بورد) وعمليات التحسين المستمرة وتشجيع بيئة التعلم بالاستقصاء.

2. العمل على قياس المخرجات والنتائج المتعلقة باستخدام التعليم عبر الإنترنت (البلاك بورئل بورد).

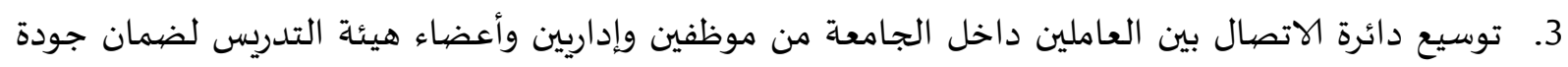

$$
\text { التعليم عبر الإنترنت (البلاك بورد). }
$$

4. البحث عن المعوقات ووضع الحلول المناسبة لها لتحقيق الأهداف والجودة في العملية التعليمية عبر الإنترنت

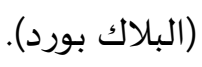

5. تطوير مهارات أعضاء هيئة التدريس والطلاب على حد سواء عبر الإنترنت (البلاك بورد).

6. التأكيد على التطوير المهني لعضو هيئة التدريس عبر الإنترنت (البلاك بورد).

7.

8. استخدام التقنيات والحلول المبتكرة الأخرى مثل الذكاء تقنية الذكاء الاصطناعي وتطبيقها لتطوير المنظومة

التربوية. 
- احمد، اماني (2006) "أثر تعلم العلوم بالأنشطة العلمية الاستقصائية في فهم الطلبة للمفاهيم العلمية ومعتقداتهم واتجاهاتهم نحو العلم"، أطروحة دكتوراه غير منشورة، جامعاة عمان العبربية للدراسات العليا،

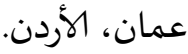

تسهيل التعلم المرن عند اضطراب التعليم " التجربة الصينية في الحفاظ على استخدام التعلم في ظل تفشي

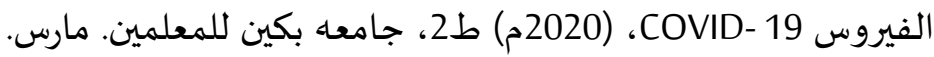
التقرير الاسبوعي الثالث عن سير التعليم الإلكتروني (2020) بجامعاه الأمير سطام 22-26 مارس، الماندان المملكة العربية

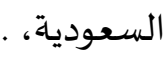
- ـ الحافظي، منى (2008). "مدى استخدام أعضاء هيئة التدريس في جامعة الملك خالد بن عبد العزيز في المملكة

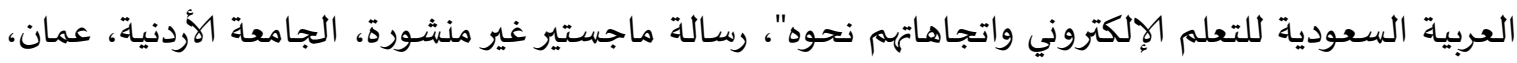
الأردن.

حجازين ميشيل (2006). أثر استخدام استراتيجية تدريس قائمة على الأنشطة العلمية في التحصيل وتنمية

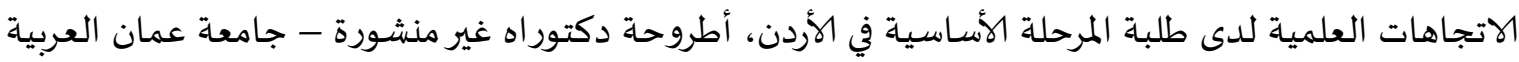
للدراسات العليا، عمان، الأردن. حشمت، رمضان (2008). فاعلية التخاطب الصيوتي والنصي بالفصول الافتراضية التزامنية على رفه مستوى الانجاز لطلاب المرحلة الإعدادية. رسالة ماجستير غير منشورة، جامعة حلوان، جمهورية مصري العهبية العربية.

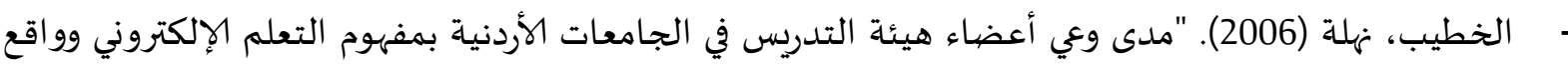
استخدامه في التدريس"، أطروحة دكتور اه غير منشورة، الجامعة الأردنية، عمان، الأردن.

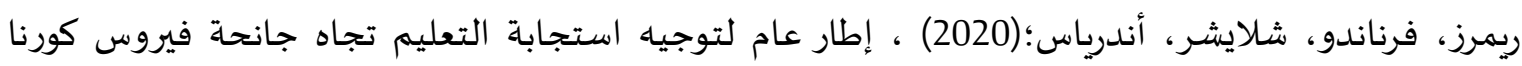

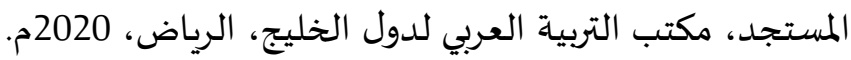
زيتون، حسن(2005). التعلم الإكتروني- المفهوم- القضايا- التطبيق- التقييم. الرياض: الدار الصولتية للنشر والتوزيع. - سالم، أحمد(2009). الوسائل وتقنيات التعليم المفاهيم والمستحدثات والتطبيقات، ط(1)، الرياض: مكتبة الرشد.

شرف، فاروق (2006) ، "آفاق التعليم الافتراضي الفلسطيني، ودوره في التنمية السياسية (نحو جامعة افتراضية فلسطينية)"، رسالة ماجستير غير منشورة، جامعة النجاح الوطنية، نابلس، فلسطين.

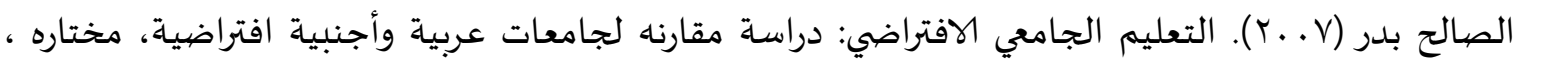

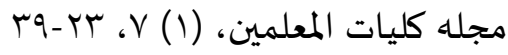
ضمان جودة المؤسسات في سد الفجوة للتعليم عن بعد في حالة الطوارئ عبر الإنترنت (2020م)، ط2، الولايات المتحدة الأمريكية. 
- العبادلة، حسام حمادة سعيد (2007) "أثر استخدام ثنائية التحليل والتركيب في تدريس الفيزياء على تنمية

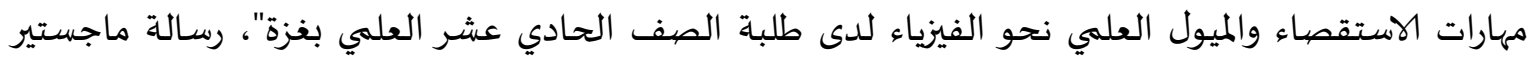
غير منشورة، كلية التربية، الجامعة الإسلامية، فلسطين عبد المجيد، محمد (2005). منظومة التعليم عبر الشبكات، عالم الكتاب، القاهرة.

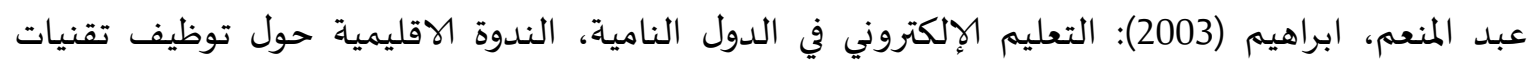
المعلومات والاتصالات في التعليم، الاتحاد الدولي للاتصالات، مركز المعلومات ودعمم اتخاذ القرارات, القاهرة.

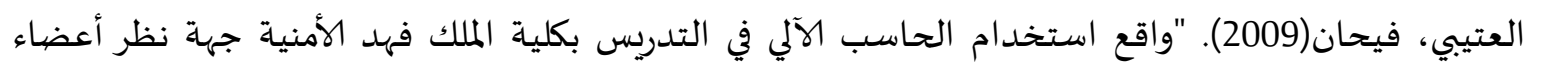
هيئة التدريس واتجاهاتهم نحوه"، رسالة دكتوراه غير منشورة، جامعه أم القرى، مكة المكرمة، السعودية المانية.

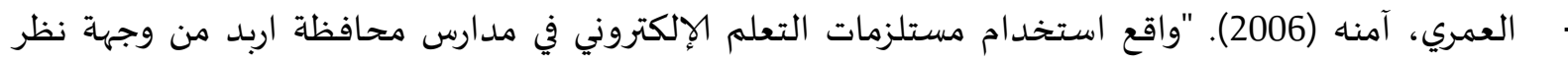

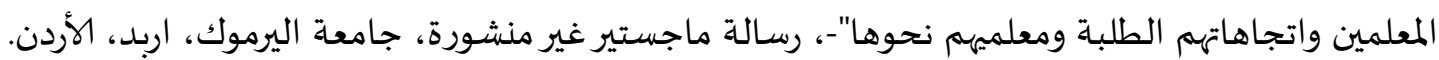
الغملاس، خالد، (2020) الفصل الدراسي الاستثنائي في الجامعات السعودية والتدريس الطارئ عن بعد، مجله جامعه الأمير سطام بن عبد العزيز

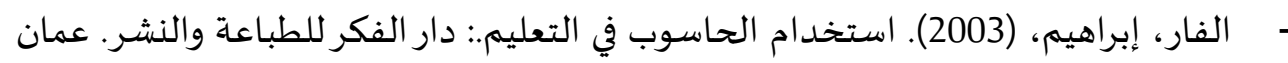
- المؤتمر الاستثنائي الافتراضي في ظل جانحة كورنا وضمان استمرارية الحق في التعليم وتبادل الخبرات لعودة

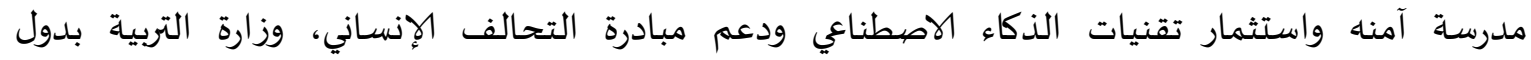

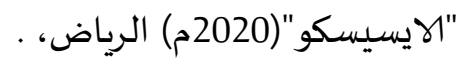
- الهاشم، عبد الله (2014). "أثر التدريس بنموذج الاستقصاء في تنمية للتفكير العلمي والاتجاهات الايجابية نحو القضايا البيئية لدى طلبة المرحلة الثانوية بدولة لكويت"، (مجلة العلوم التربوية والتقنية)، المجلد15(2): 535-

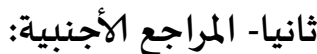

- Ambikaiarajah, E\& EPPS, J \& Shen, M \& Celler, B. (2008). A New Mode of Lecturing for Self-Directed Learning - Virtual Classroom on DVD, AiP Conference of American Institute of Physics

- Berg. C., Anders, R., Bergendahl, V., Christina, B., \& Lundberg, B. K.S. (2003, March). Benefiting from an open end Experiment? Comparison of attitudes to, and Outcomes of, an expository versus an open inquiry version of the same experiment, International Journal of Science Education, 25(3). 351-372.

- DICTIONARY OF COVID-19 TERMS, Arab Organization for Education, Culture and Science, Arab Coordination Office, Rabat, Morocco, 2020. (English - French - Arabic)

- GAO. S. (2010). Science teacher' belief of inquiry instruction and its impact on practice: A case study of Chemistry teacher in China. Paper presented at the Annual Meeting of the 54th Annual Conference of the Comparative and International Education Society. Palmer House Hotel. Chicago Illinois

- Jackson. D. B. (2010) Exploring the impact of the epistemological beliefs of science teacher on authentic inquiry: a multiple-case study. Paper presented at the annual meeting. Hilton Chicago. 11 
- Mayer, J. C.(2009). Implementation of inquiry- based pedagogy significantly improves student achievement. Paper presented at the annual meeting of the mathematical association of America Mathfest. Portland Marriott Downtown Waterfront Portland.

- McBrien, J \& Jones P \& Cheng, R (2009). Virtual Space: Employing a Synchronous online Classroom to Facilitate Student Engagement in online Learning international Review OF Research in Open and Distance Learning

- Windschitl. M. (2003) Inquiry in projects in science teacher education: What can investigative experiences reveal about teacher thinking and eventual classroom practice? Science Education,87(1). 112-143

- Zhong, B. (2008). Thinking along the cultural line: an inquiry of ethical decision-making among U.S and Chinese journalism students. 